THE

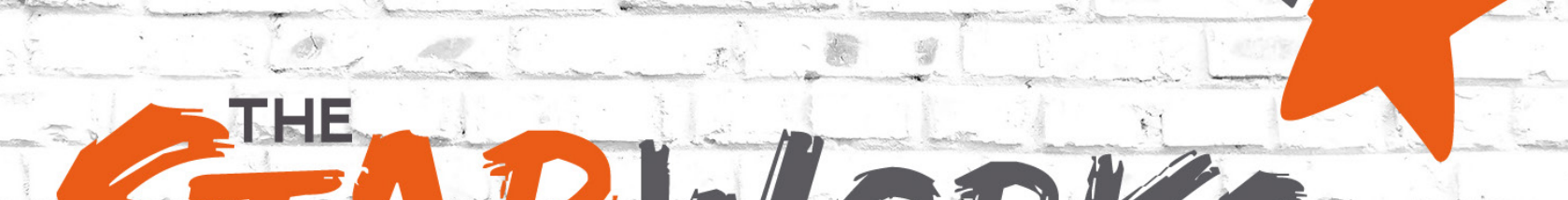

\title{
ANNUAL REPORT TO NATIONAL INSTITUTE FOR HEALTH RESEARCH 2018-2019
}

Nathaniel Mills, Gemma Wheeler and Joe Langley https://doi.org/10.7190/starworks-NIHR-1819 


\section{CONTENTS}

\section{Executive Summary}

Overview of progress made during 2018-2019

Leadership, governance and management arrangements

The Starworks Proof of Concept projects

Added value

Starworks 2

Dissemination and raising the profile of Starworks

Patient and Public Involvement, Engagement and Participation

Top Three achievements during the 2018/2019 financial year
04

05

06

07

19

20

22

24

26
List of Appendices

1 -Additional detail on the experience and outcomes of the PoC projects

2 - Outcomes and Added Value from the Industry Forums

3 - Images for the Starworks Celebration Event

4 - Tools created to collect feedback or ideas from children and families 


\section{EXECUTIVE SUMMARY}

Since its inception, the NIHR Child Prosthetics Research Collaboration (Starworks) has applied an inclusive and responsive approach to engaging the stakeholder community (including academics, clinicians, industry experts and, crucially, children and families), ensuring their voices shape the project direction as well as the research priorities it supports.

This is evident in the project journey so far (where collaborative 'Sandpit' event themes were informed by an initial, multi-stakeholder needs assessment) and is also reflected in the diversity of Proof of Concept (PoC) projects that it has funded through an open application process. The projects covered a range of topics, including comfort, customisation, information needs and efficiency of electric limbs, and were approved by a multidisciplinary panel of judges, including representatives of related charities.

\section{This reporting period has seen:}

- Funded proof of concept projects nearing completion

- Continued profile raising of the Starworks network and the vital importance of new and innovative research for children with limb loss

Further research funding to develop and grow the network to January - 2020 (Starworks 2)

Starworks 2 followed on from Starworks 1 and began in January 2019. Our aims are to:

Support the best of the funded projects from Starworks 1 to allow the outputs to reach children and families and make a difference for the child living with a prosthetic limb.

Support new ways of working across stakeholder groups to produce cutting edge research methods for clinicians, academics and inc the NHS to accelerate development towards clinical use.

Develop sustainable processes such as a database of unmet needs, methods of capturing relevant information, and a research-ready register of clinicians, centres and families that would be willing to collaborate to enhance child prosthetics.

Work with funders from across the funding spectrum to offer sustainable and long-term research approaches and methods for stakeholders to utilise.

Work with industry to explore mechanisms that help them to bridge the gaps between innovative development and adoption into practice.

\section{OVERVIEW OF PROGRESS MADE DURING 2018-2019}

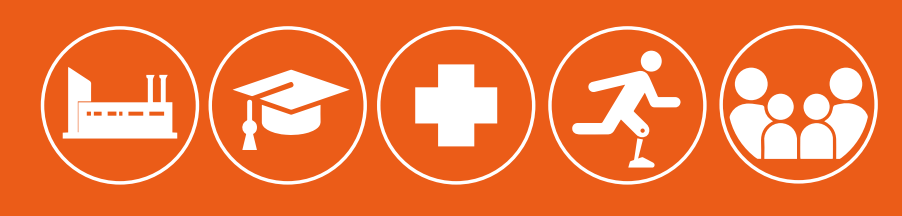
New Collaborations across diverse stakeholders

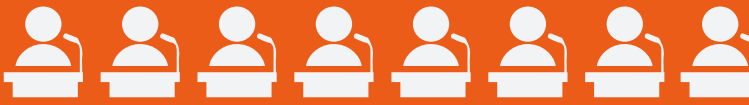 88817 conference}

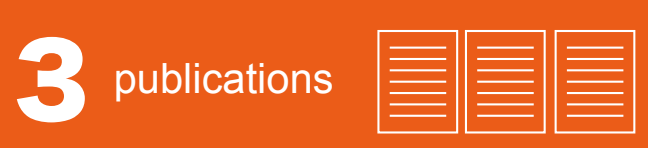

5 posters

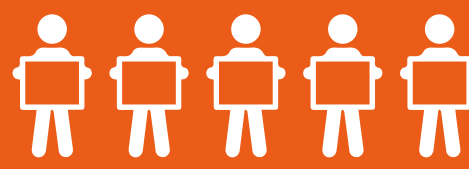
OP

Near completion of

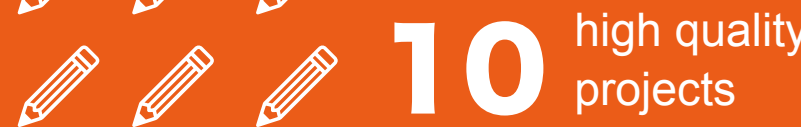

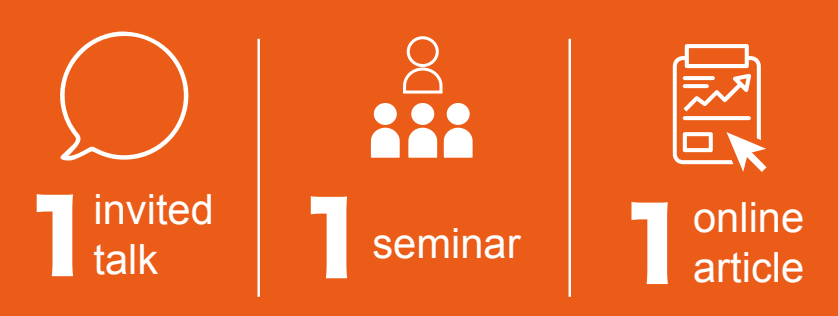

Support of Limbpower's

FUNdamental Skills Day

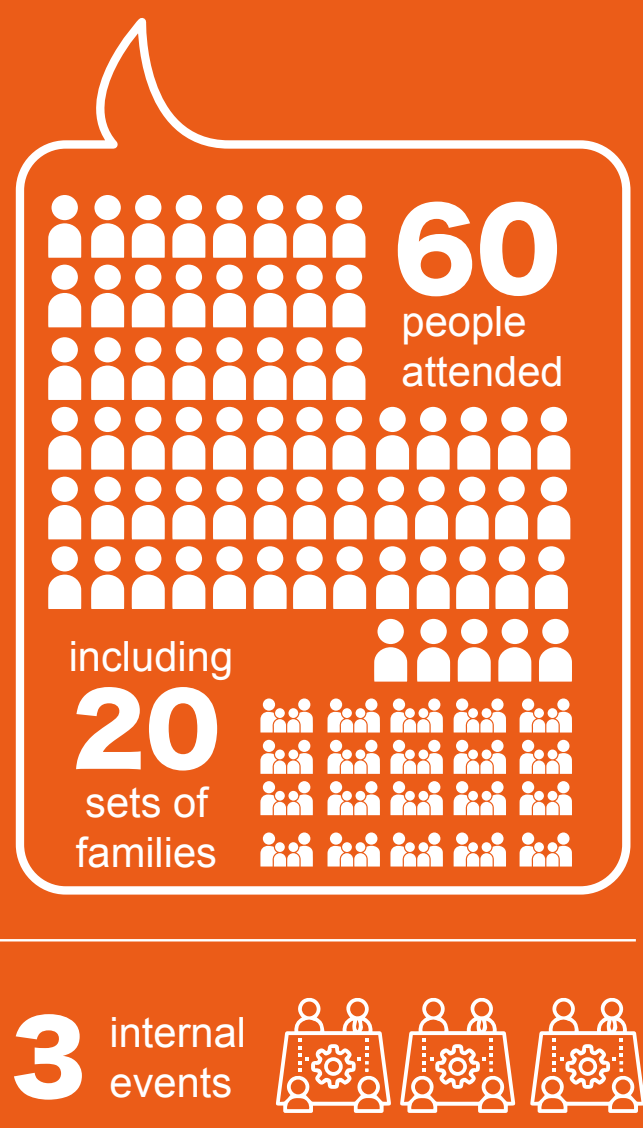




\section{LEADERSHIP, GOVERNANCE \& MANAGEMENT ARRANGEMENTS}

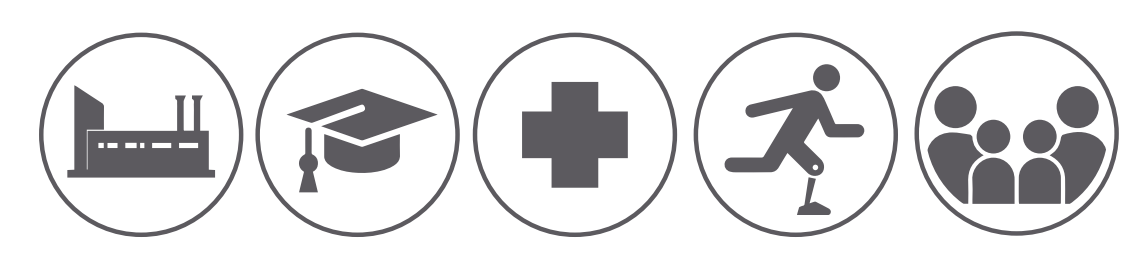

In order to ensure all stakeholders are represented a Project

Reference Group (PRG) was

established. This provides

transparency, focus and guidance.

The PRG is a multidisciplinary

team of key opinion leaders in

the field and include families and

charities. A particular challenge

with the PRG over the reporting

period has been the retirement

of some of the members and

others moving on or changing

role. However, this has been

offset with growing this group to include representation from the British Association of Prosthetists and Orthotists (BAPO) - who develop standards for prosthetic and orthotic practice - and new clinicians who have an active interest in the development of innovations in the field. The Starworks project is managed by the NIHR Devices for Dignity (D4D) team and reports to the D4D Steering Committee three mes a year.

As host for D4D, Sheffield Teaching Hospital NHS Foundation Trust provide been invaluable in providing guidance for the proof of funding project allocations and specific ethics questions that have arisen around the individual projects. governance support and have
The Starworks call for applications for 'Proof of Concept' funding to address key challenges within Child Prosthetics technology and provision was launched in September 2017. Applicants were asked to consider a co-design, cross-sector collaboration, which is evidenced within the submitted applications.

When the funding call closed, 23 high quality project proposals had been received, including 14 from academia, 7 from industry/ SME's and 2 from charities. Of these proposals, 7 related primarily to socket improvement; 3 to lower limb development; 9 to upper limb development; and 4 to development of information sources. Notable aspects were:

The themes explored within our initial sandpit events were clearly evidenced throughout the applications, with a large number focusing on the socket interface as well as lower prosthesis

personalisation and adaptability.

Many applications focused solely on upper limb prosthetic applications.

- A small number addressed cross-sector communication and the journey a child takes through the prosthetics service.
The majority of applicants offered significant support in kind and matched funding through partner institutions.

The main thrust of Starworks has been the funding support offered to collaborative groups to help develop new innovations for children who require upper or lower limb prosthetics.

This reporting period has seen the commencement and near completion of the projects. Throughout, the Starworks Network continued to apply an inclusive and responsive approach to supporting the $\mathrm{PoC}$ projects. Whilst some projects operated more independently that others, careful monitoring via progress reports and regular contact by email anticipated potential issues in advance, with support offered on a case by case basis. This support has included guidance on ethical review, questionnaire design, regulatory frameworks and signposting to further resources.

Each project is summarized overleaf. Further details on the potential benefits to children and families, the challenges of and recommendations for conducting research in this area, and new unmet needs identified by the Starworks PoC projects are provided in appendix 1. 
Project 001

University of Southampton

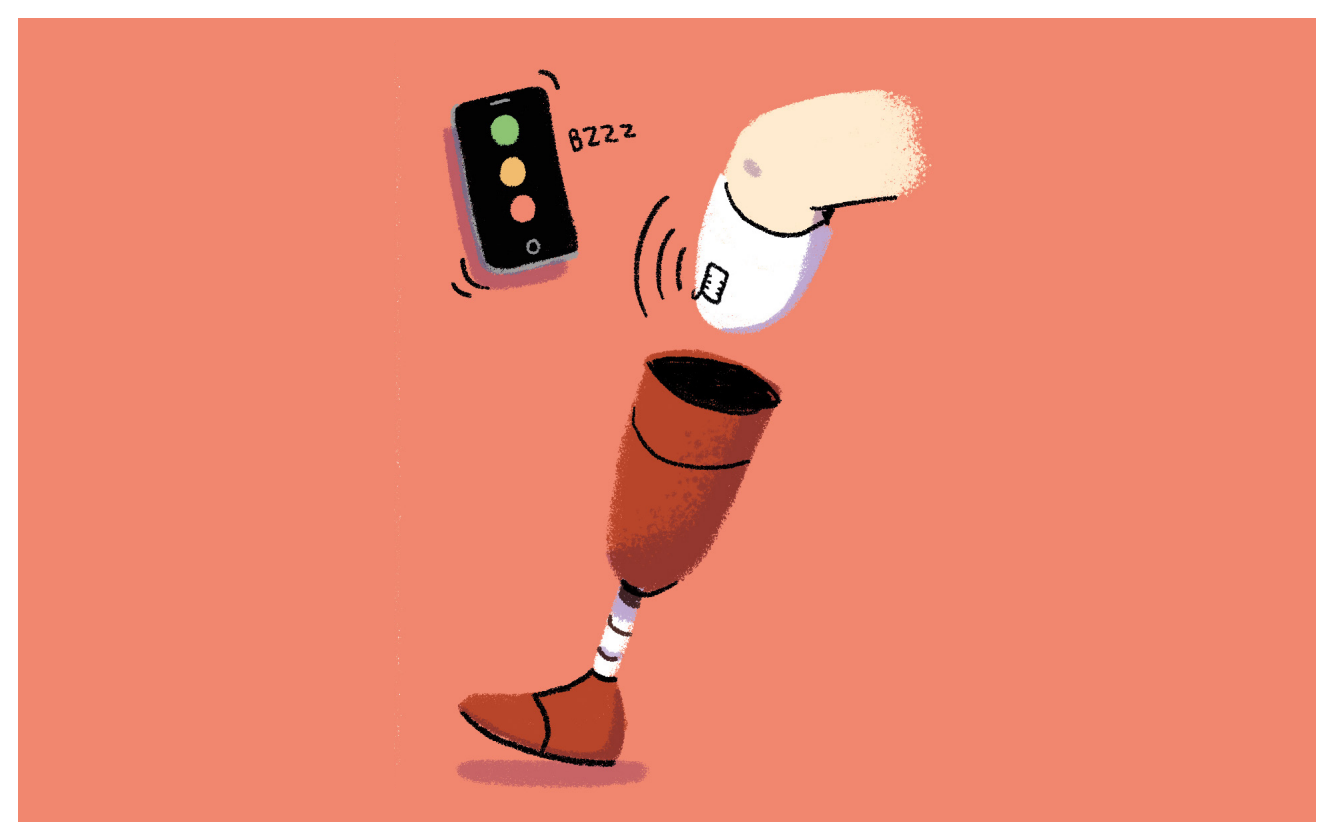

Key take away message: A new socket fit monitoring tool to help alert children, their parents and clinicians for timely socket adjustments.

Project 001 developed a first-of-its-kind Socket Interface and fit Monitoring System (SIMS) for children with lower limb absence, using a system of sensors in the socket and a smartphone app to help identify the appropriate time for socket adjustments. The team have engaged 15 children with limb losses and their families as well as 8 clinicians to identify the key design criteria. Subsequently, an initial proof-of-concept was implemented incorporating Southampton's novel interface sensors and a parent app, with positive initial feedback. The team have also created a first ever stump/ socket simulator mimicking real world loading conditions for a child amputee, to validate the SIMS capability of monitoring socket fit changes over childrens' limb growth. Looking towards future development of the project, childrens' SIMS has already successfully passed the pre-compliance electromagnetic compatibility tests, and the team have developed a network of stakeholders who are supportive of further work, including children, families, clinicians, surgeons, lower limb rehabilitation engineers, stakeholders from industry and charitable organisations. In addition, the team has developed a regulatory road map for the downstream development.

\section{Project 002}

Steeper Group

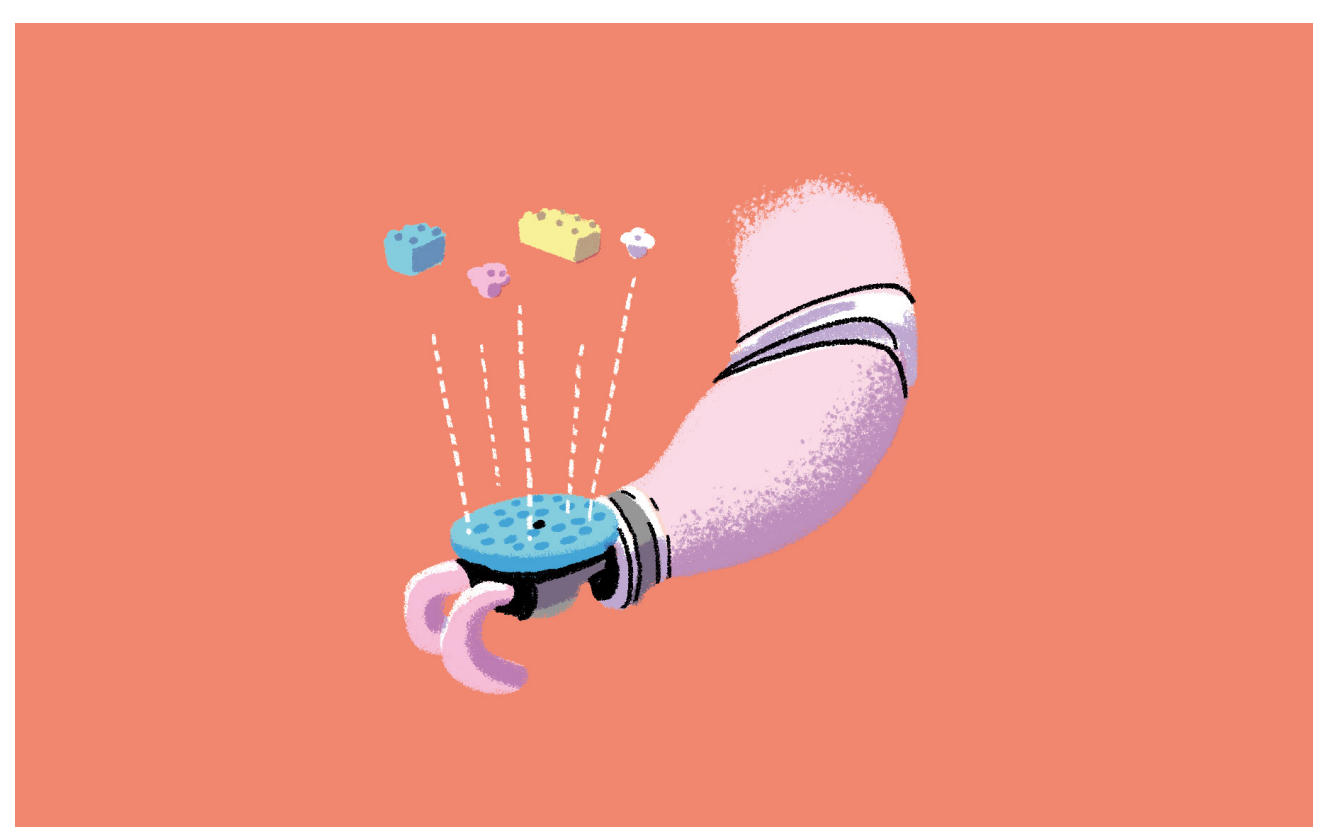

Key take away message: Transforming functional hand prostheses to be more acceptable to children, and toward a more 'toyful' aesthetic.

Project 002 delivered a reliable clip-on Lego® platform (Play Attachment) to sit on top of a children's split hook hand prosthesis. This aims to make the prosthesis more playful and fun, to encourage children to wear it for longer or more frequently (non-wear of upper limb prosthetics impacts on a child's development and gait). The project investigated different fabrication techniques including 3-D printing to make it easy to use and ensure unaffected prosthetic function and a quality fit to Lego parts. The project redesigned an early prototype (developed in previous clinical practice) producing CAD designs and 20 milled usable left- and righthanded platforms compatible with Lego pieces, as well as a high-quality 3-D printed platfoms compatibinted demonstrat possible next steps include applying for ethical approval to pernit a small study to evaluate the impact of the play attachments for young split hook users. 
Project 004

Limbpower

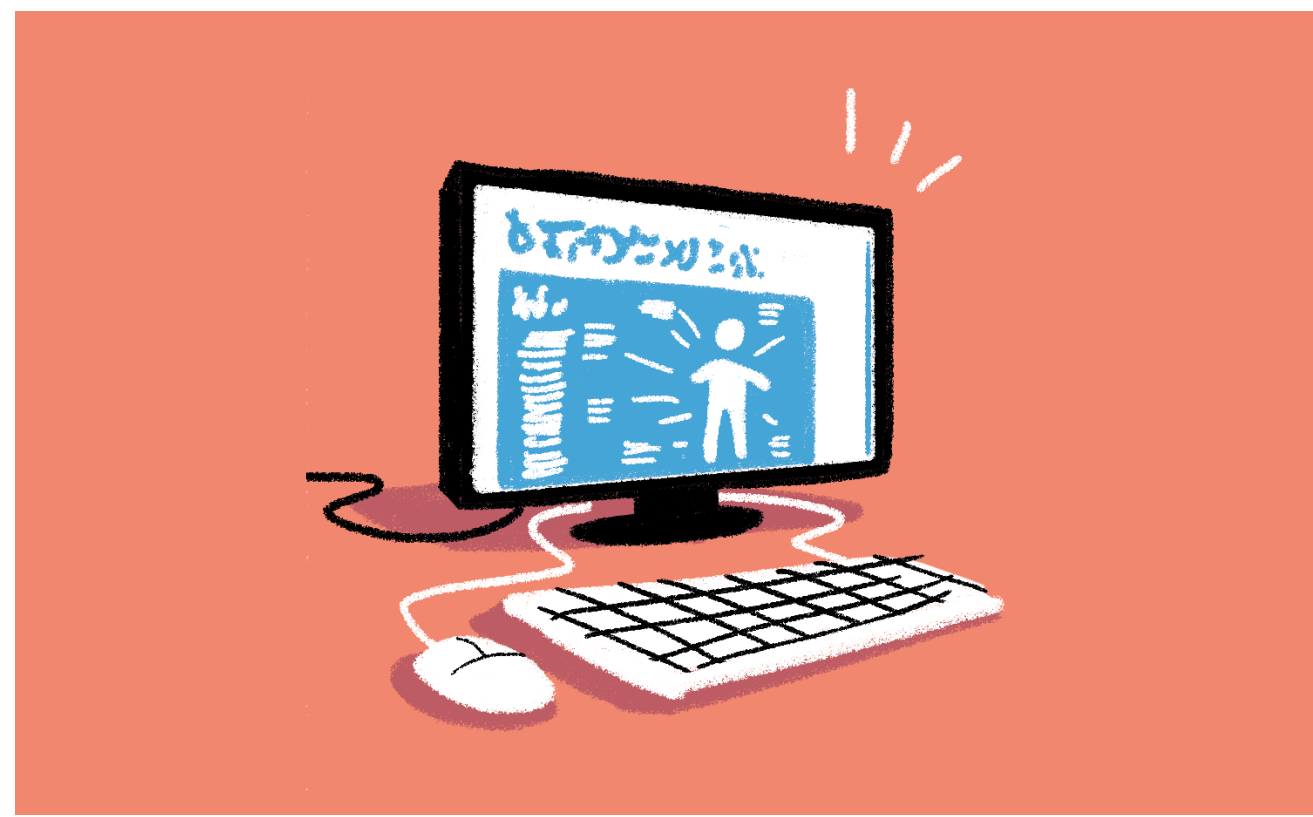

Key take away message: Limbformation will be a 'one stop shop' for all families including a child with limb difference.

Project 004 aims to develop 'Limbformation' - a 'one stop shop' website for families and children with limb loss or limb difference, supported by educators working with these families. The purpose is to empower, support, and educate through factual information and personal stories. Progress so far includes conducting extensive surveys across all stakeholder groups and running two family focus groups to establish website content. The team has also agreed a contract with a website builder as well as submitted and approved a wireframe, style, logo and front end of the website. The team will then upload text, images (including infographics responding to child and parent priorities) and information.

\section{Project 006}

Newcastle University

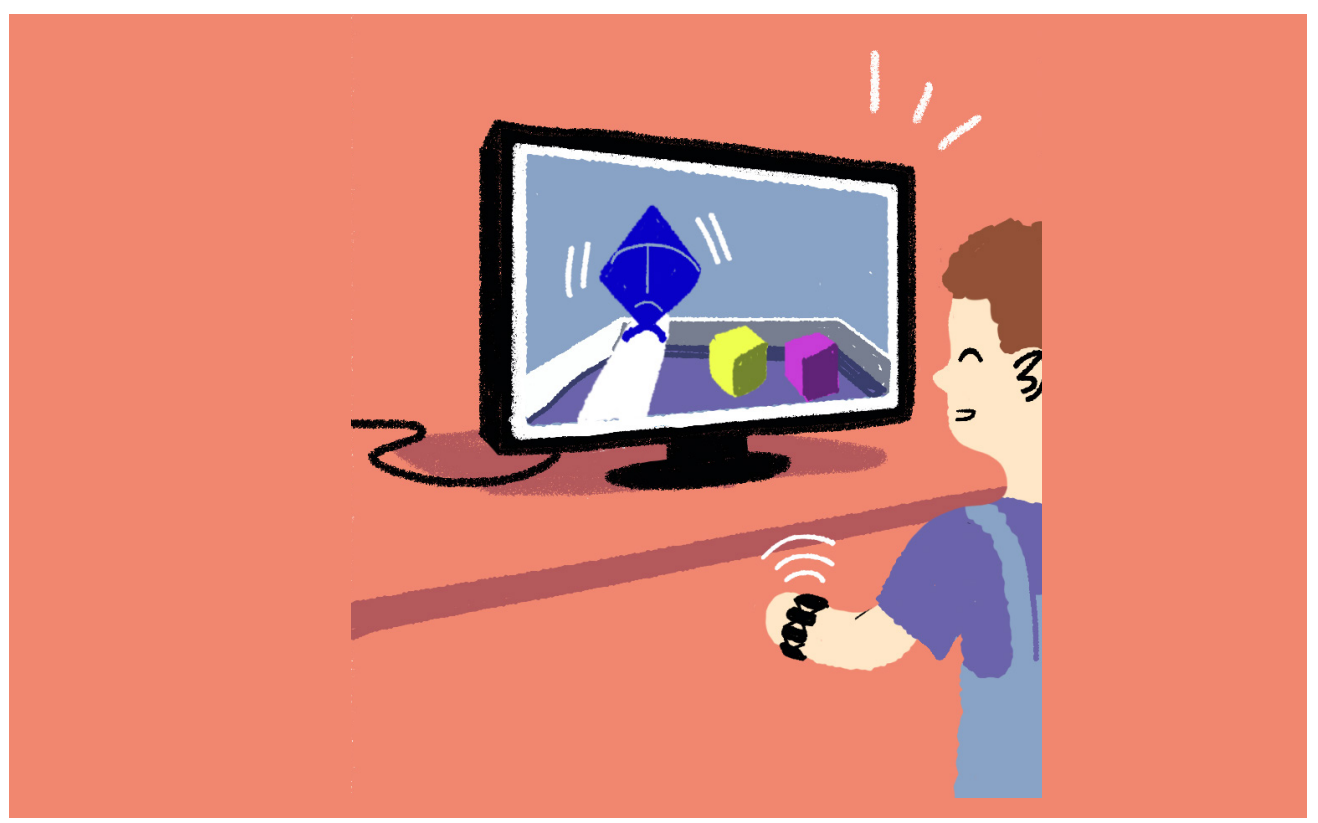

Key take away message: We want all children who get prosthetic hands to be able to control them properly so that we can show that these hands can make a difference.

Project 006 aimed to address the high rejection rates of electronic upper limb prostheses in children, who can find them difficult to control using conventional training methods. By using a videogame format to visualise and give real time feedback on the muscle signals needed to control such prostheses, children learn to master producing novel forms of muscle activity. The child learns how to play the game prior to prosthesis fitting and operation, and the team hopes this will not only increase the uptake of electronic limbs but also their functionality (i.e. how many grips/movements the child is able to perform). The team have created a fully functional rototype game and have elicited further. To the best of our knowledge, this is the first game-based system for urther. To the best of our knowlem for upper-limb prosthetics which provides direct continuous feedback regardin muscle activity for motor learning, and has the potential to greatly reduce costs to the NHS with regard to training and uptake of these limbs. 


\section{Project 009}

Manchester University NHS Foundation Trust

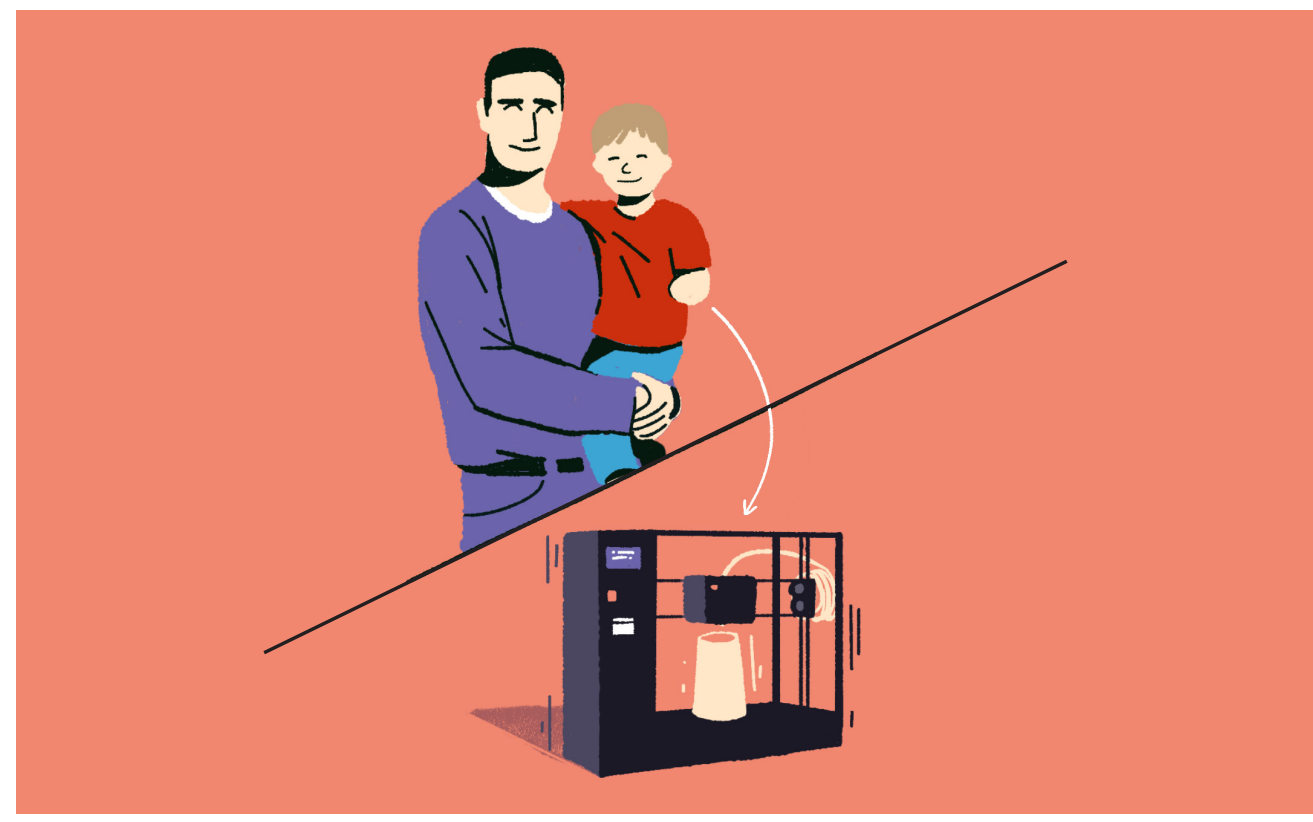

Key take away message: The 3D printed prosthetics are developed to engage and inspire infants to help improve adoption comparable to the current NHS offering.

Project 009 aims to develop 3D printable prosthetics for infants with uppe limb differences. A complete set of $3 \mathrm{D}$ printable prosthetics has been manufactured, to fit a child patient's dimensions, socket adaptors to connect to NHS socket and hand attachments with locking mechanism (attachments are playful and designed to encourage wear of the prosthetic, including a flashing bear, a rattle and a variable grip device, to attach to a scooter for example). The final products have been reviewed by the clinical team and two trials have taken place within a NHS Prosthetic Centre. The 3D printable prosthetics can be scaled in size to grow with child development and could prosthetics can be be cus mised futher (colour, mate to families design brief ideas.

\section{Project 010}

Cambridge Prosthetics Ltd

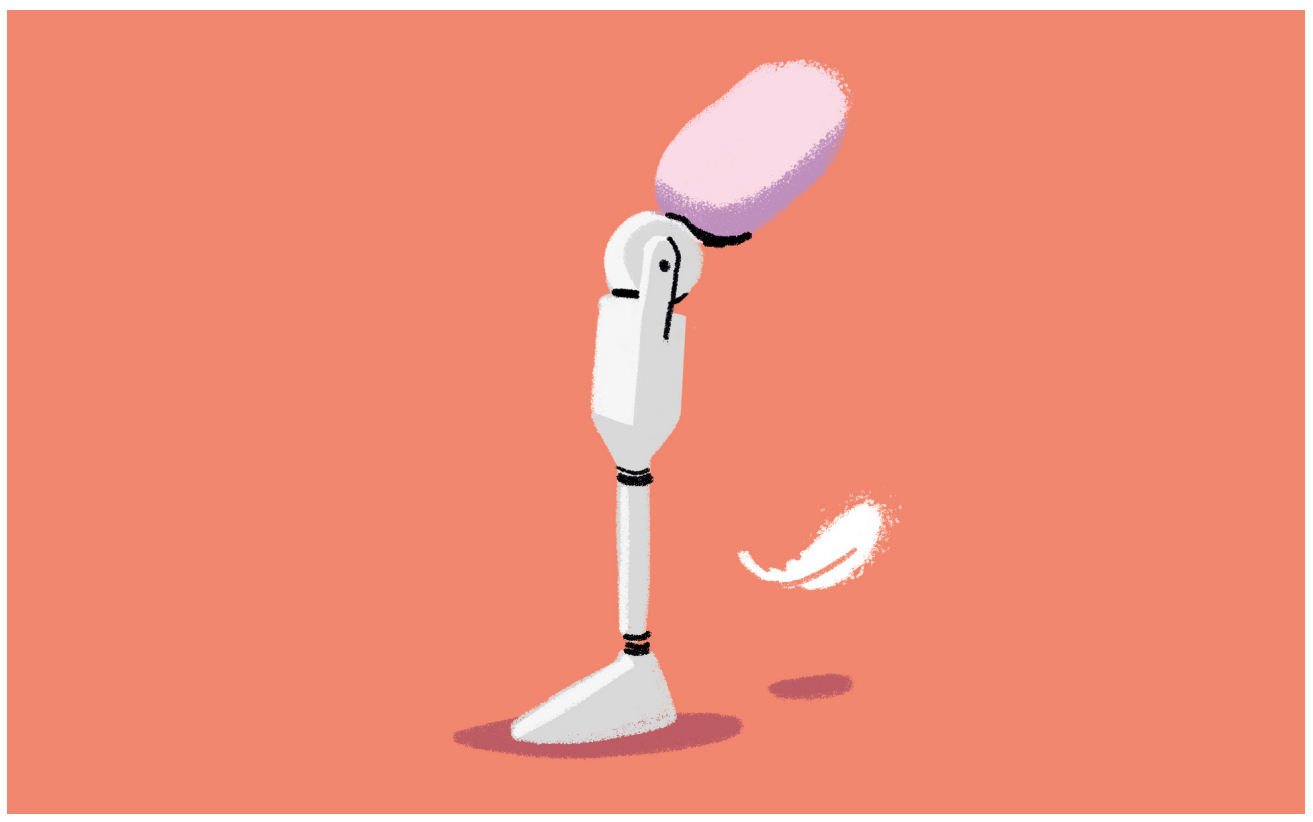

Key take away message: The key feature of the knee is that it is designed to enable children with an above knee amputation to take part in play and other activities alongside other children.

Project 010 aimed to develop a new prosthetic knee for children which uses the natural properties of specialist materials to more closely mimic a natural leg rather than relying on pistons, electronics and robotics typically employed in adult legs to compensate for their weaknesses. The team have produced a prototype knee which is lightweight $(450 \mathrm{~g}$ compared to the NHS standard of $770 \mathrm{~g}-885 \mathrm{~g}$ ), easily maintained, waterproof, and bends up to 140 degrees thus providing extra flexibility for children in play. The knee can also be rotated sideways to enable sitting with crossed legs, and sitting on the floor. The team have submitted a patent application for novel aspects of the for. The tean 2010 . The next stages involve deving a plan for the design in January 2019 . The next stages involve developing a plan for 


\section{Project 014}

Loughborough University

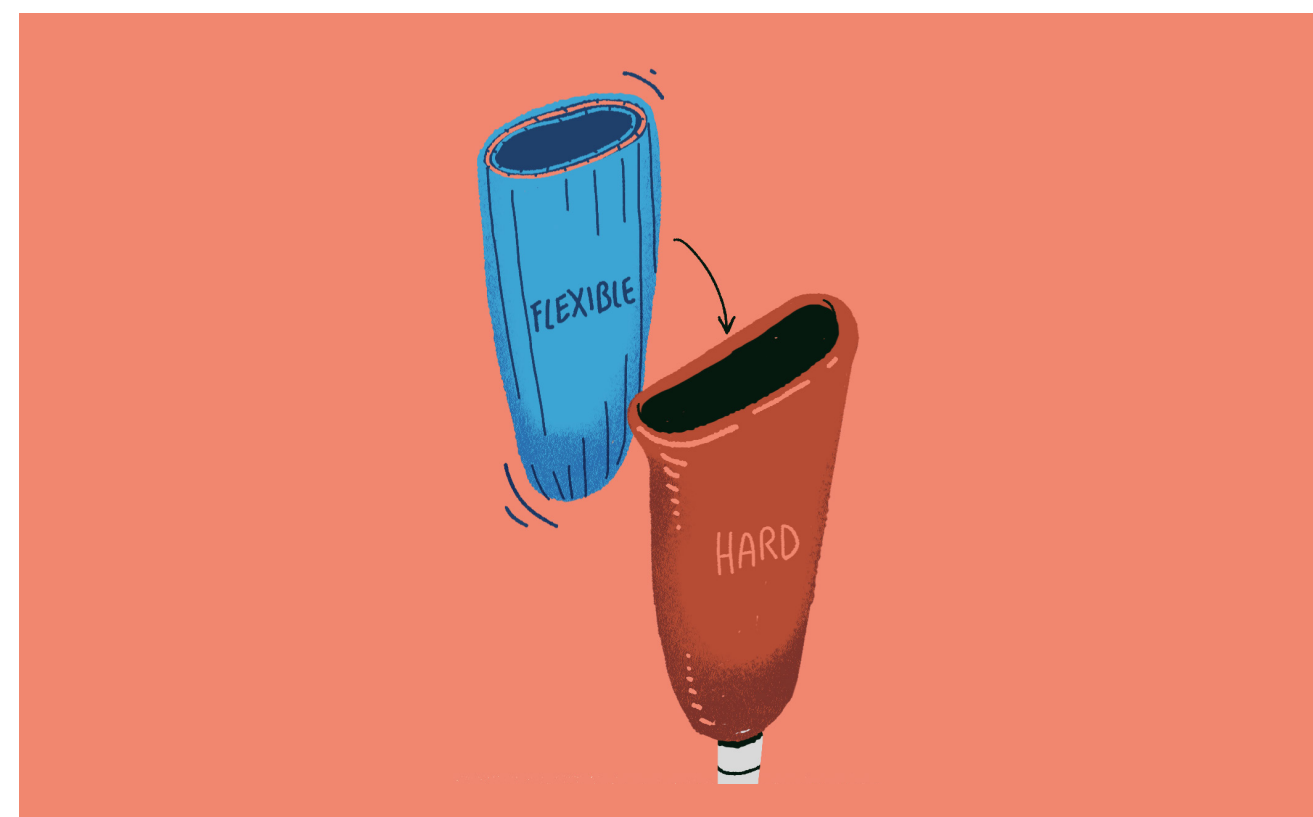

Key take away message: The novelty of the project is to create a scientifically validated design and manufacture workflow that will provide children with comfortable and adaptable socket and liner components, which will be bespoke and at a fraction of the current cost.

Project 014 aimed to address the age-old challenge of developing a robust prosthetic socket that is also comfortable and adaptable to growth, by designing and making socket and liner components from advanced biocompatible, composite materials via digital manufacturing methods. Over the funded period, the team have: Developed a proof-of-concept, modular prosthetic socket; Conducted an extensive literature survey to identify suitable materials and $3 \mathrm{D}$ printers for additive manufacturing of prosthetic sockets; Designed and dever sockets; Desians atible compos 3 atriater range of $3 D$ printing materials, Developed a full parametric CAD package to automatically generate personalised sockets from 3D scanning data of the residual limb; Manufactured a range of proof-concept sockets; and conducted a range of mechanical tests of the manufactured components.

\section{Project 016}

University College London

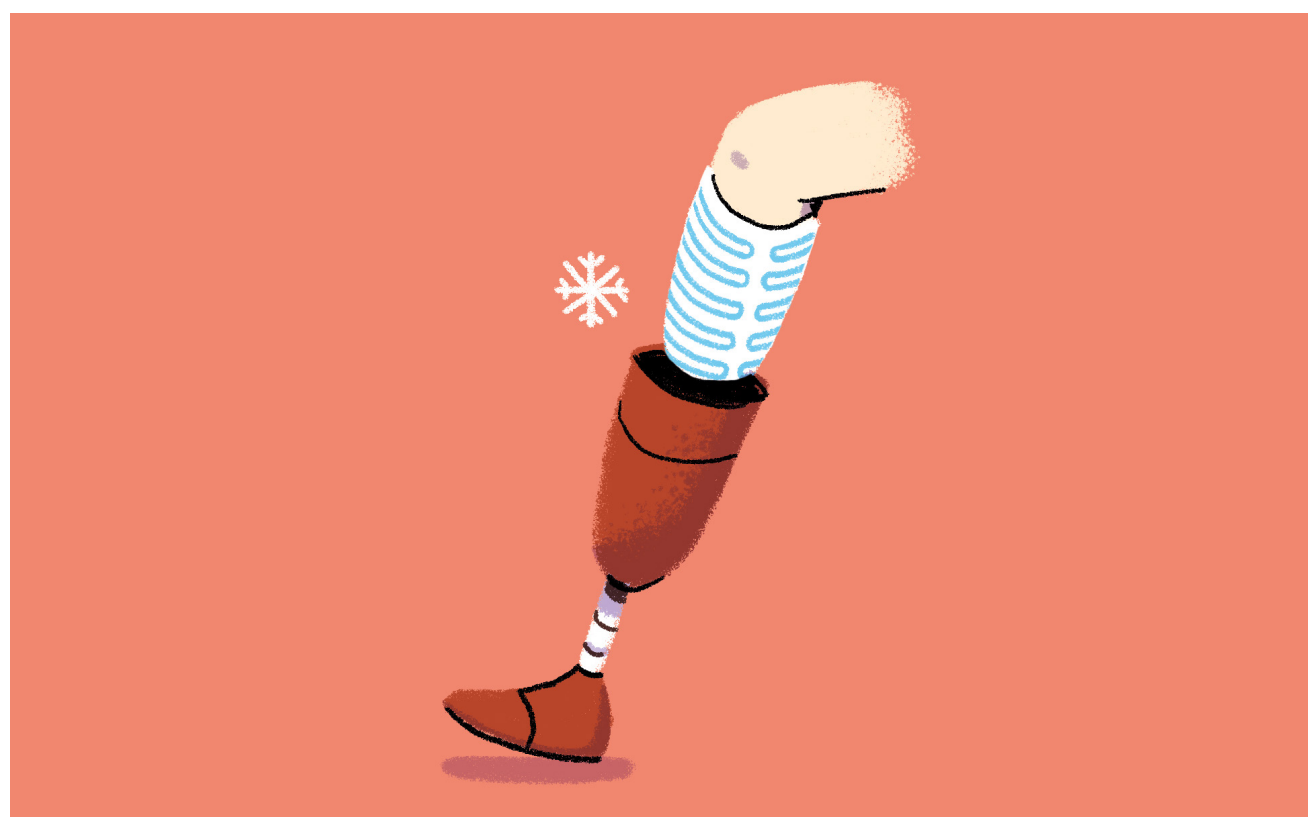

Key take away message: Through our work we hope to improve the satisfaction of children with their prosthetics, reduce skin infections, and reduce rejection rates.

Project 016 aimed to develop a method to 3D print bespoke silicone liners for child prosthetics wearers in order to address issues of comfort and performance for those children as they grow. The team were able to develop a method for the low-cost production of bespoke socket silicone liners, which was successfully tested by creating a full size prototype (based on the scan of a 10 year old patient). The team also developed a novel method to rapidly print cooling fluidic channels within silicone socket liners. A working prototype liner with an embedded cooling system was made using this method, which was the validat by thermal tysting. this method, which was then validated by thermal testing. The team have produced methods to calibrate and 3D print carbon nanotube-silicone stretch sensors into liners, demonstrating their potential to monitor changes in size and volume of stumps on a daily and long-term basis (to inform scheduling of refitting sockets). The team will continue to develop these soft wearable technologies under a wider project the Global Disability Hub, UCL - https:// www.disabilityinnovation.com/consultancy/at-2030-assistive-technologyscoping-exercise 


\section{Project 018}

University of Salford

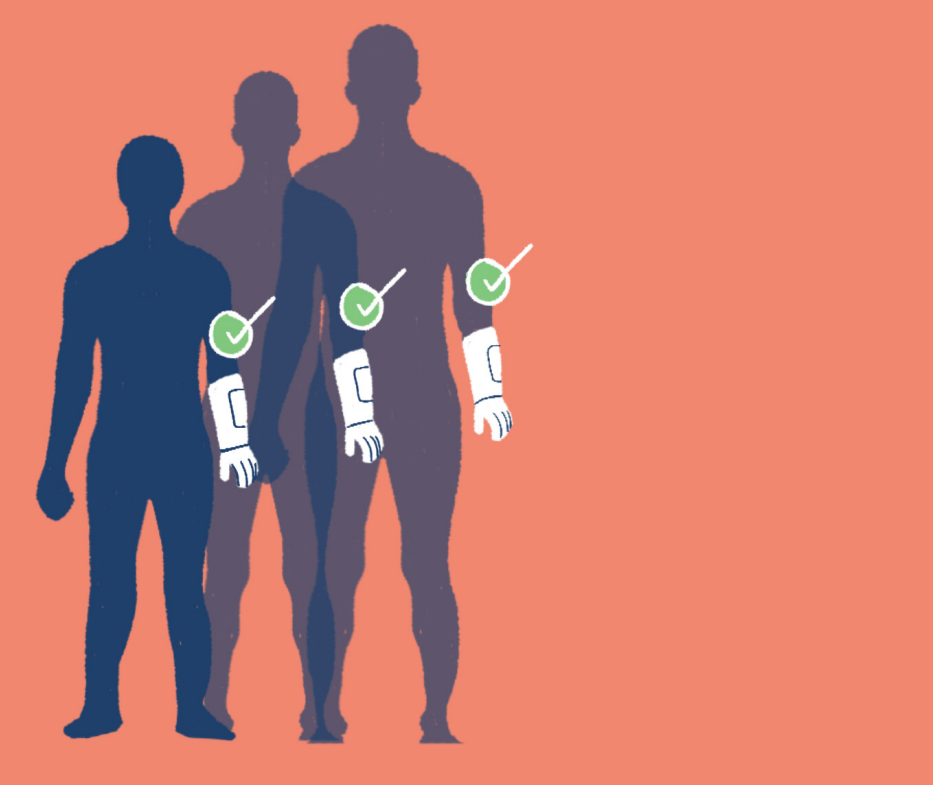

Key take away message: We anticipate that by allowing adjustments to electrode pressure and orientation, the overall functionality and contro of myoelectric prostheses will be improved.

Project 018 aims to develop a user-friendly device that will allow parents and prosthetists to improve myoelectric prosthesis electrode pressure and alignment on the skin's surface (addressing key factors in electronic upper limb rejection rates). The team have designed and fabricated (using 3D printing) a working prototype of an adjustable electrode housing device that can be used in conjunction with a standard clinical myoelectric prosthesis that achieves these aims. The device has been validated by testing on four transradial (upper limb) prosthesis users. The team believe their designs

may be patentable and are seeking advice from a professional IP office. Nex steps involve collaboration with another Starworks team (016) to develop the concept further, including size reduction and testing with children.
Project 020

Opcare, Abiltiy Matters, University of Strathclyde

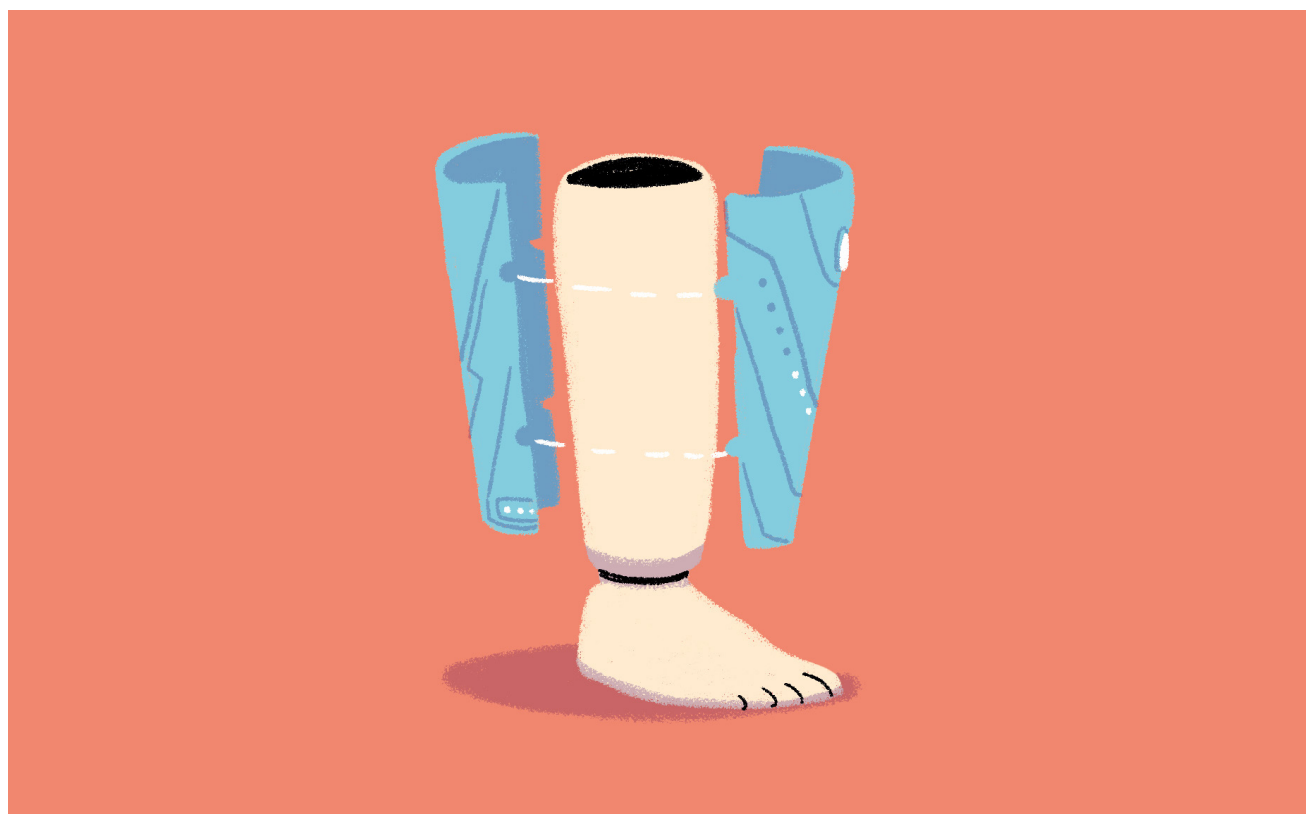

Key take away message: Designing a cover will be a fun process that improves the child's engagement with the prosthetic rehabilitation pross, promotes positive discussion with the child's family and process, promotes positive discussion with the child's family and friends, and we think will change the perception of the look and appeal of children's prostheses.

Project 020 aimed to develop affordable, high quality 3-D printed

customisable covers for children's prostheses that are easy to remove or

change according to the child's choice and activity. Progress to date includes background research (investigating the use of 3D printing in prosthetics and any existing, similar products), design work (identifying the optimal method of CAD shape capture, materials and printing methods), extensive software analysis and comparison, manufacture of a range of prototypes and the team are currently undertaking a clinical trial to evaluate up to twelve covers. 
PROJECT CHALIENGES \& FEEDBACK FROM TEAMS

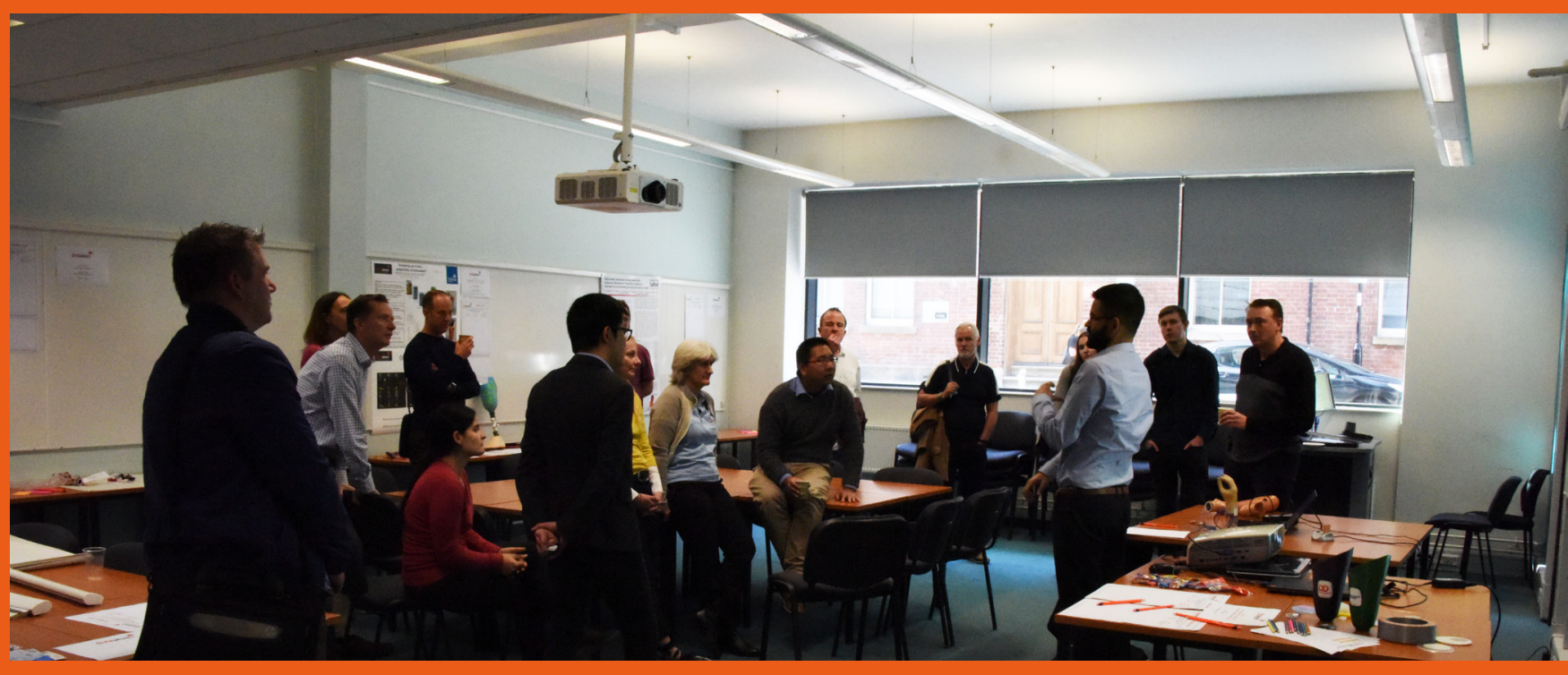

These projects faced multiple challenges, something that the Starworks team looked to address through our open and supportive approach. The main challenges echo those mentioned in the Industry Forum discussions discussed in the next section (and in Appendix 2), i.e. seeking ethical approval to involve families in research, access to families and children, etc. This highlights the importance of bringing these groups together to learn from each other's experience, and the role of the Staruorks team in providing additional guidance and support, as demonstrated in the quotes below from several PoC teams' final report:

"We feel that the support from Starworks team has been excellent and we have benefitted tremendously from the support from Starworks network, without which we would not be able to achieve our current results and links to our collaborators, industrial partners and stakeholders." - 014

"The sandpits were an excellent way to develop ideas and the follow-on meetings were very useful for getting feedback on progress." - 016

"The support from the Starworks team has been very helpful. They have been very understanding, approachable and supportive throughout the process." - 020

An added benefit from this approach has been the way multiple groups have collaborated across projects to stimulate new innovations and developments in this field.

\section{ADDED VALUE}

Industry Forums

Through D4D's partner, the University of Sheffield, the

Starworks team successfully applied for MRC Proximity to applied for (PR Proxinity to a funding scheme is designed to foster the establishment of new collaborations by specifically providing support for early interactions and knowledge exchange between external partners and academic researchers.

The Starworks Team proposed to tilise the P2D support by hosting uthise the P2D support by hosting a series of meetings for the $P$ project teams, and individuals from related research areas, to meet and share experiences, knowledge and ideas. We invited academics from the University of Sheffield, the University of Salford the University of Newcastle and Sheffield Hallam University to the events in order to identify new areas for collaboration. new areas for collaboration. The 'Industry Forum' meetings took place on 9th July 2018 and 20th October 2018 in Sheffie Representatives from all of the $\mathrm{PoC}$ projects attended one or both meetings, where they shared their progress to date, any challenges they had faced and techniques for overcoming these challenges. The meetings promoted a sense of community between the different project ens as well as collaborat teams as we as collaborative problem solving in this (relatively new) area of research. Indeed, joint funding applications have been submitted to external funding bodies between $\mathrm{PoC}$ projects as a result of these meetings. A more detailed summary of the outcomes of these meetings can be found in appendix
Match Funding

Prior to the announcement of 'Starworks 2 ', some projects leveraged other sources of funding in order to ensure continuation of their projects. This includes:

002 - The project lead's employer, Steeper Group, assisted financially with reimbursement of travel expenses, printing and funding to allel expenses, allow the lead to attend conferences.

006 - Part of the initial Starworks application was funded by a $£ 15 \mathrm{~K}$ EPSRC Impact Acceleration Account from Newcastle University. The project lead has also secured a five year Newcastle University Research Fellowship to continue working in this area. The team are currently at the second stage of an ORUK bid for £100K to fund a postdoctoral researcher to work on gameplay and motivational aspects of the project for two years. They are also in discussion to access further Newcastle University EPSRC Impact funds in order to address sensor development, with an anticipated cumulative value of $£ 50 \mathrm{~K}$. At minimum one $\mathrm{PhD}$ student will begin contributing to this project from October this year; these studentships are typically valued at around $£ 60 \mathrm{~K}$.

014 - The team leveraged £5

additional funding to contribute towards development of a new printer head and chamber which will be used to conduct work in the next phase. The team were also granted additional funding from Wolfson School Research student internship (June to August 2018: £2812) ind the Applied to August 2018: 2812 ) small equipment grant for additive manufacturing $(£ 5000)$.

016 - The team obtained additional funding and support from the EPSRC Vulnerable Skin Network (https://www. southampton.ac.uk/mdvsn/index.page ) and support in-kind from the Royal National Orthopaedic Hospital in the form of prosthetist consultant time, access to patients, and 3D scanning technology. https://www.rnoh.nhs.uk/ 


\section{STARWORKS 2}

Starworks 2 is building on the significant challenges and opportunities identified and opportunities identified In Starworks 1. The continuation and development of expert networks with the relevant stakeholder groups will allow Starworks 2 to nurture exciting ideas and collaborations to enhance research and development in this area. In collaboration with our partners we will continue to empower and champion the to empower and champion the voice of the children and their for the . A major aspect of this for the network to move towards sustainability by communicating its value to the wider UK innovation landscape and seeking ther sour la will include engagement with the relovant funding the UK to identify and stimulate opportunities for future funding calls that align with the wider Life Sciences and Industrial Strategies, with the UKRI strategic plans, with the NHS Long Term Plan and with the established Starworks network priorities. We norvorions  opportunities to become a health social enterpi network.

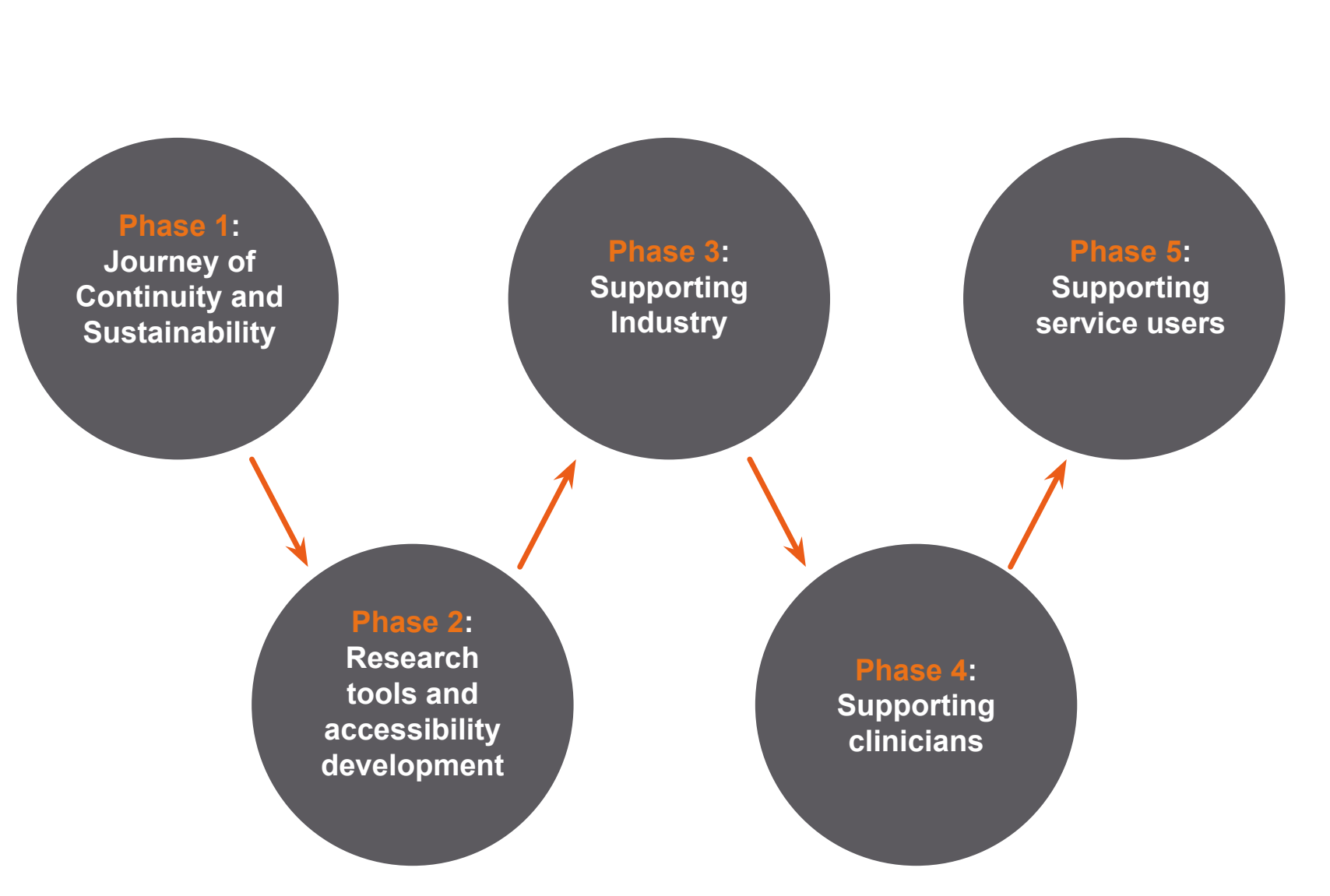

20

\section{PHASES OF STARWORKS 2}

The five phases of Starworks 2 our summarised below:

Phase 1: Journey of Continuity and Sustainability

Phase 1 will see the launch of a funding call to provide ongoing support to the best proof of

concept projects from Starworks 1. The focus of this will be around applicants showing progress and demonstrating a plan of action that identifies areas for significant further development. It is anticipated that the majority of funded projects from Starworks 1 will not be in a position to apply for larger grants at position to apply for larger grants at this stage; therefore this phase wil support the best projects to enable them to be in a position to do so at a later stage.

Phase 2: Research tools and accessibility development

Phase 2 is supporting the development of tools to enhance research in the present and future within the field of child prosthetics. There are a limited number of validated outcome measurement tools for researchers and throughout Starworks 1 our stakeholders told us that this is a barrier to identifying and developing new research foci in child prosthetics. The collaboration will work with experts within human factors disciplines, academics and industry to support the development of valid, sensitive and reliable tools to measure outputs relevant to research in this area. Such tools
co measure outputs relevant to research in this area. Such tools
could measure, for example, pain and comfort when looking at the limb interface; an accurate physical activity measure for children with a prosthetic; and effect(s) on activities of daily living for children with limb loss.

\section{Phase 3: Supporting Industry}

Phase 3 is working with our partners to focus on the elements that enable the collaboration to spread its reach and have a meaningful impact on the lives of children who use a prosthetic limb. This phase will involve work with both SME's and larger companies operating in this space to engage in open access research aimed at benefitting the wider child prosthetics community. Engaging with established companies operating in the field of prosthetics provision, and also those providing expertise in areas such as additive manufacturing and computer aided design, provide two examples that would be key to this provide tro examples that would be key to this approach. This would refiect the approach taken by some of the innovative SME's operating in th space who work on an open source basis and make the technology available to those who want to develop it further.

Phase 4: Supporting clinicians

Phase 4 is engaging with clinicians to explore training needs of healthcare professionals and to support them in the day-to-day delivery of care for children who use prosthetics. It will also explore how clinicians can reach out to their colleagues and peers to share best practice and unmet clinical needs. In addition, the collaboration will partner with leading Universities to investigate how it can support the training of prosthetists to a) help academia and education delivery, and b) consider a research pathway for graduates in the future.

Phase 5: Supporting service users

Phase 5 seeks to maintain and enhance the support from the children and families we engaged in Starworks 1 to focus on acquiring a broader 'real-life' evaluation of prosthetic usage. This will encourage research into areas that are closely linked to actual prosthetic usage. It will also enable children to be collaborators within the research to allow for greater transparency and accuracy when measuring outcomes. 


\section{DISSEMINATION \& RAISING THE PROFILE OF STARWORKS}

- The Starworks Network was invited to present the achievements to date and opportunities to get involved at the International Society for Prosthetics and Orthotics (ISPO-UK) Annual scientific meeting, 12 - 13 October 2018

- The Starworks Network and launch of Starworks 2 was presented at Trent Internationa Prosthetics Symposium 22nd March 2019

- The work completed in Starworks 1 was used as the basis of a workshop exploring alternative outcome measures for child prosthetics at the European Academy of Design Conference, Dundee, 10th-12th April 2019. This attracted an international audience from the field of design, the outcomes of which will contribute to the deliverables of Starworks 2 (see below).

Conference posters:

002 - 2nd place poster prize at BAPO conference 2018

002 - Poster presentation Trent International Prosthetics Symposium 2019 006 - Poster presentation at the International Society for Prosthetics and Orthotics (ISPO-UK) Annual scientific meeting, 12 - 13 October 2018 010 - Initial results presented at recent meeting of the International Society for Prosthetics and Orthotics (ISPO-UK 2018) 018 - Poster presentation at the International Society for Prosthetics and Orthotics conference at University of
- Two members of the Starworks team have been invited to co-author a book chapter titled 'Prosthetics for Children' in the forthcoming Institution of Engineering and Technology book titled 'Control of Prosthetic Hands: Emerging avenues and challenges' edited by Kianoush Nazarpour.

- Our Starworks celebration event on the 25th March 2019, invited all of the funded projects to attend - all but 2 projects attended, we also hired a professional Live Illustrator to give the projects an instant output to support their own dissemination (see appendix 3 ).

- The Starworks PoC projects have contributed to raising the profile of Starworks through their various dissemination activities, including:

Conference presentations:

001 - Tang J, Jiang L, Meng Z, Hale N, Head J, Twiste M, Morley E, Moser D, Zahedi S. "A preliminary study of socket interface loading and socket fit for children with lower limb absence", ISPO Annual Scientific Meeting, Southampton, Oct. 12-13, 2018. 001 - Tang J, Jiang L, Moser D, et al. Monitoring socket fit for children with lower limb absence. ISPO ASM. Salford, UK: ISPO, 2019 006 - "Low cost at home myoelectric training using biofeedback and off-theshelf hardware," Mathew Dyson and Kianoush Nazarpour. Internationa
(ISPO) 2018

006 - "Home-based myoelectric training using biofeedback gaming," Matthew Dyson and Klanoush Nazarpour. Trent International

014 - Allen T (2018) Bioinspired auxetic materials for sports equipment $\mathrm{Bio}-$

inspired Materials Conference 2018, 10 th October 2018 at Manchester Metropolitan University.

014 - Shepherd, T. (2019) Auxetic

materials for sports equipment, Sport

Engineering Seminar Day 2019, 31st

January 2018 at Loughborough University

016 - Research on 1D stretchable sensors presented at Robosoft 2018 (April 2018) 016 - UCL Cross-Disciplinary Network on Soft Materials Presentation (June 2018) 016 - Research on 2D stretchable sensors to be presented at MRS Society Conference 2018 (Nov 2018)

016 - TIPS2019 Conference paper on bespoke intelligent liners with cooling. 018 - Oral presentation on the results of the work was delivered at the 2019 Trent International Prosthetics Symposium (https://www.trent-prosthetics.com/wpcontent/uploads/2019/01/TIPS-ISPOBACPAR-final-draft-programme.pdi)

Seminars:

014 - Li, S (2019) Towards next generation personalised prosthesis socket manufacturing, 21st March 2019 at Defence Health and Medicine Meeting, Stanford hall, DMRC, UK.

Invited talks:

001 - MSc Amputation and Prosthetic Rehabilitation study day - 'Celebrating Advances in Prosthetic Componentry', 7 December 2018

Internal events (Hospital staff training, university lectures, etc)

02 - Presentation at Steeper Upper Lim training day, October 2017, Harold Wood Long Term Conditions Centre

006 - Overview of project, Child

prosthetics lecture: Newcastle University 3th December 2018

18 - Oral presentation on the results of the work was delivered as part of the leve 6 (third year) undergraduate Prosthetics and Orthotics teaching programme at the University of Salford on 21-2-19.

\section{Magazine articles:}

002 - Article published in the British Asscociation of Prosthetists and Orthotists (BAPO) magazine February 2018 edition available on request)

02 - Online article published in the OandP Edge Magazine (available at: https://opedge. com/Articles/ViewArticle/2019-01-01/the-playattachment-project-rethinking-the-split-hook 014 - AATCC News: The Magic of Auxetic Materials: https://www.aatcc.org/pub/aatccnews/newsletters/0319a-story $1 /$

\section{Online articles:}

Webstory (insight piece) published The Steeper Group website, Marc 2019 https://www.steepergroup. com/about-steeper/insights/the-playattachment-project-re-thinking-thesplit/?fbclid=IwARONIsTRGgm3P dEKf7rIEL4Dk3-Y

A6XId60pC1YPRgQ015gj1hxqe7hRM

Journal papers:

014 - Smith, J. A., Mele, E., Rimington, R. P. Capel, A. J., Lewis, M. P., Silberschmidt, V. V., \& Li, S. (2019). Polydimethylsiloxane and poly (ether) ether ketone functionally graded composites for biomedical applications. Journal of the mechanical behaviour of biomedical materials, 93, 130-142. 014 - Alias, N., Smith, J. A., Kumar, J., Garnder, J., Li, S. (2019). Dynamic and degradation studies of $3 \mathrm{D}$ printed fibre reinforced composite materials for lower Iimb prosthetic socket application. Journal of Prosthetics and Orthotics (In preparation) 016 - Research paper on stretchable sensors eurrently under review for publication by the Frontiers Robotics and Al journal (https:// www.frontiersin.org/journals/robotics-and-ai\#

Public engagement:

016 - Stanmore Public Open Day, Royal National Orthopaedic Hospital, Stanmore (April 2018)

006 - General promotion and discussion at the Fundamental Skills Workshop, 29th September 2018 (see below)

06 - Oral presentation, demo and genera discussion, 'You have Been Upgraded, Manchester Science Festival,' 18th October

006 - General discussion: The future of prosthetics: a user perspective, limb-loss PP
event, 12th December 2018 


\section{PATIENT AND PUBLIC INVOLVEMENT, ENGAGEMENT AND PARTICIPATION}

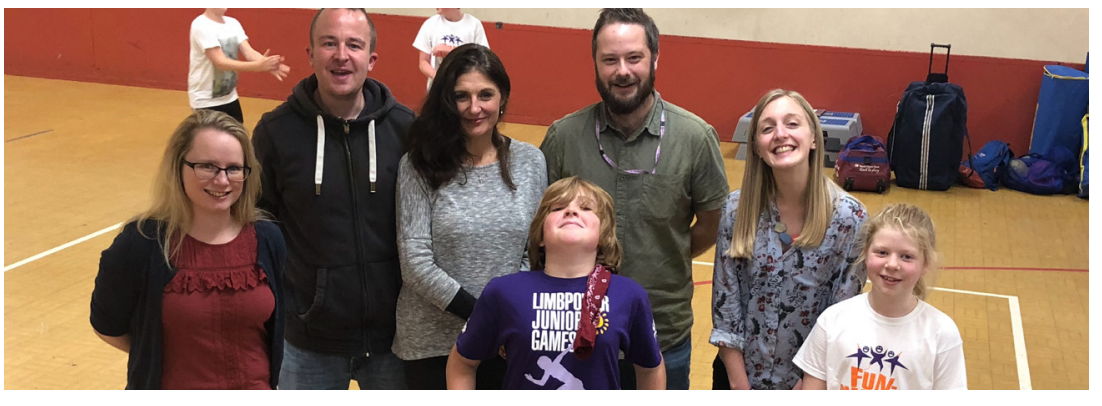

Our approach of enabling children and families to act as experts has been central to the Starworks programme. This has been evidenced within our activities during the reporting period:

We invited children and families to the second industry forum, publicising this widely and attending several external family engagement events to ramily engagement events to We also encouraged PoC projects to prepare child-friendly exhibition spaces/activities to facilitate meaningful feedback (see appendix 4). As such we feel that the network is encouraging patient-centred ways of working within the teams and provides support in designing PPI activities resources when needed.

A 'Christmas activity pack' was created by the Starworks team incorporating the tools created by the PoC teams described above. This was distributed online amongst our networks and social media to reach as wide an audience as possible.
In association with Move More Sheffield and Sheffield International Venues we supported Limbpower's SNdamental Skills Day in Sheffield. This is a workshop fo children with limb difference and amputees aged 5-18 who have an activity limb or would like to be more active. The aim is to teach children how to make the most of their prosthetic limbs to aid their perticipation in physical activity and sport both in schol activity the community. The focus in the community. The focus is very much on teaching skills for activity and skills for life.

- Over 60 people attended the event including over 20 families

- As part of the event, we invited the funded project teams to meet families and children to discuss their projects and enlist the expertise and guidance held within the expansive group.

- We also discussed with the families our plans for the Starworks network and how we could work with them to help shape the network in turn helping to stimulate activity in new innovations for children who use prosthetic limbs.

- Attending this event also introduced the team to new clinicians interested in supporting the Starworks network going forward.
The PoC project teams were encouraged to involve children and families in their work as much as possible. This was achieved in the following ways:

Questionnaires (001) (006)

- Home visits (001)

Visits outside of the home (001)

- Interviews (001)

- Family 'play days' (002)

Informal conversations in

clinical practice (002)

- User testing (006) (018) (020)

Several project teams described the importance of this input in their final reports, particularly 001 who stated:

'We have extensively engaged with children amputees and families through questionnaires and visits, which have

undoubtedly provided the most

inspiring experience and insights inspiring experience and insights
to help in the delivery of the aim throughout this project.'

Interestingly, one project's final report (016) specifically mentioned how their work was directly informed by the original Starworks Sandpit events (see previous annual report) again highlighting the importance of such PPI events even over a year later.
"We attended the event in Sheffield ...and I cannot praise this event highly enough! It has helped my daughter - above knee amputee so much...in physical and psychological terms. The coaching was excellent; supportive, encouraging and empowering. I am so glad we made the effort to attend the event, even though it was a distance to travel it definitely worth it. Additionally, I would also say it is so lovely for parents and say it is so lovely for parents and carers to be able to catch up and discuss how we support our limb different children and how we can have a voice on future research and innovation priorities"

- The FUNdamental Skills event was well received, as demonstrated by this feedback from one mother of a 10 year old girl using a lower limb prosthetic.

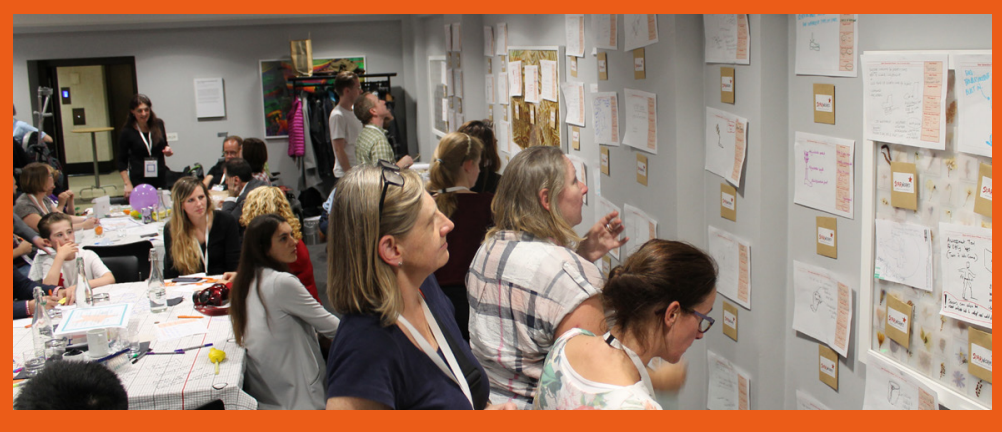




\section{TOP THREE ACHIEVEMENTS \\ DURING THE 2018/2019 \\ FINANCIAL YEAR}

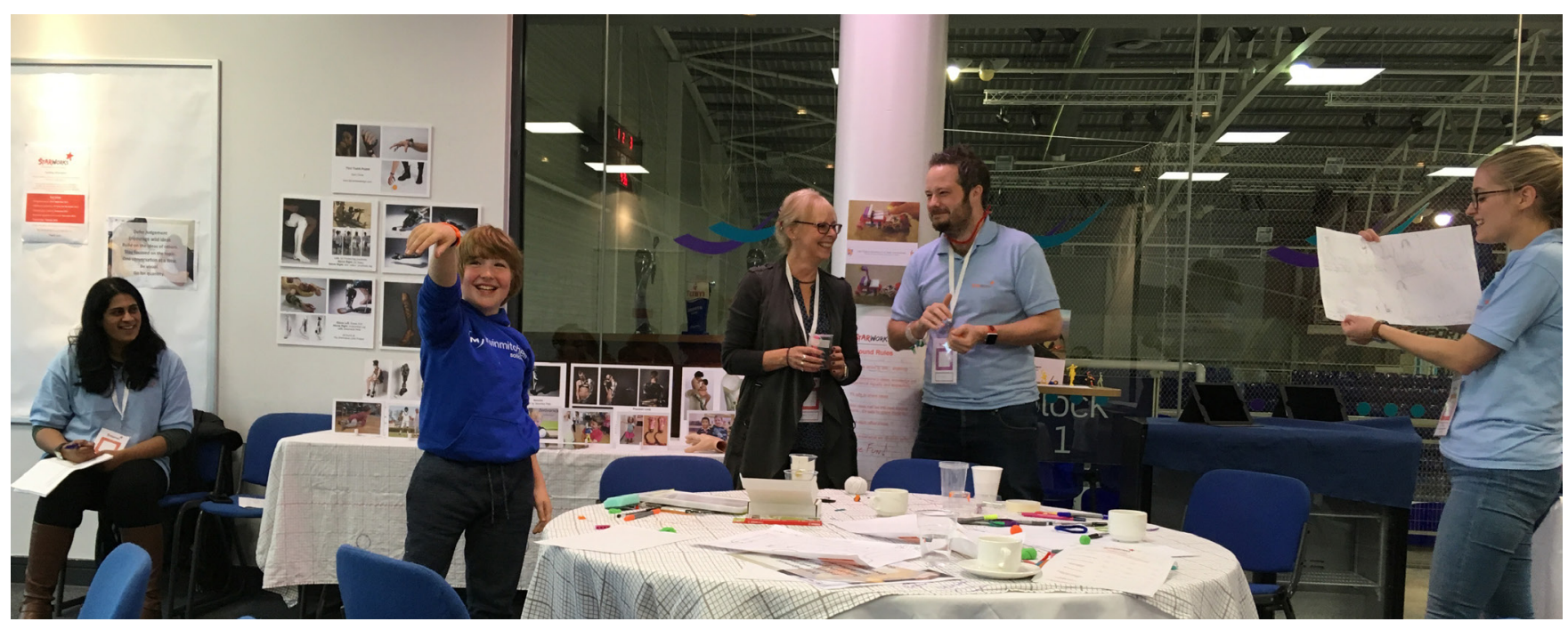

The near completion of 10 high quality projects developed as a direct result of the sandpit events held in Starworks 1. These projects have addressed a range of high impact unmet needs for the child population raising the profile of this crucial area of research whilst also generating novel solutions to the issues at hand. The monitoring and support

provided by the Starworks team has also generated rich insights into the challenges of conducting research in this area from clinical, academic, industry and family perspectives. This learning can in turn be fed back to the funding bodies to enhance and promote research in this area in the future.

The new collaborations that have grown out of the network to pull together diverse stakeholders to develop new innovations and developments in child limb prosthetics. A collaborative approach has been central to every aspect of the Starworks Network to date and will continue

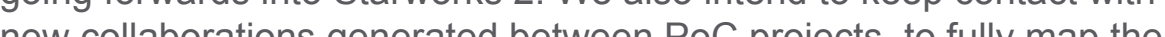
fully map the impact of this initial funding.

The further funding that has facilitated the growth of this exciting programme. The Starworks Team now has the excellent opportunity to further explore some of the key issues arising from Starworks 1 as well as develop the sustainability of the network beyond this funding window, whilst ensuring the voices of children and families remain at the centre of what we do. 


\section{projects}

\section{Overall benefits to children and families as a result of Starworks PoC projects} Enhanced socket fit and/or comfort

The Starworks Project has identified from an early stage that improvements in this area could potentially lead to reduced demand on NHS services by reducing secondary complications caused by poor socket fit. Several projects achieved benefits in this area in the following ways:

- Through real-time biomechanical measurement at the stump/socket interface (001)

- Identifying 'hot spots' of poor fit within the socket (001)

- Predict new socket replacement ahead of time (001)

- New, 'objective' data sets regarding socket fit to support consultations and socke creation (001) (014)

- Through personalized fit of socket liners (014) (016)

- Through breathable socket liners $(014)$

- Through active cooling of socket liners (016)

Through socket structures that accommodate volumetric change (over the course of a day) and limb growth (over time)

Additional methods to reduce demand on NHS services

- The development of a low cost rapid production method for the fabrication of bespoke socket liners from 3D scan data (016)

Potentially improved uptake of upper limb prostheses

Advances in this area may also have clinical benefits related to development and gait.

Several projects discussed developments in this area, in particular:

- Through new, 'playful' interactive features (002) (009)

- By enhancing usability of electronic upper limb prosthetics, through enhanced fit/signal communication (018) or by reducing the cost needed to train children in the use of electric upper limbs (006). This may make electronic upper limb prosthetics more likely to be available on the NHS in the first place.

Reducing the time needed to be taken out of school

An initial needs assessment conducted by the Starworks Team early in the project identified a key challenge related to the time children and families need to take out of school or work respectively. This is often due to the rapid growth rate of children and therefore the need to refit the prosthetic socket regularly (where each re-fit may need more than one visit). Several projects suggested contributions in this area in the following ways:

- By providing richer data to clinicians regarding socket fit, and anticipating when new sockets will be needed ahead of time (001)

- By facilitating independent training in the use of electronic limbs at home (006)

- By providing reliable/repeatable, less labour-intensive work on manufacturing the socket in clinic (014)

- With an approach that hopes to remove/speed up/decrease the price of some aspects of the process of fitting a new device (016)

How to 'Let kids be kids!'

Several projects touched on one of the original themes from the Starworks Sandpits in 2017 - how to let kids be kids with a prosthetic limb? This included:

- New ways of keeping things simple. This manifested in different ways across the projects, including drawing on advances in technology (i.e. using new polymers instead of complex knee mechanisms in Project 010, or using 3D printing to create new socket structures that self-adjust to accommodate growth and air-flow in Project 014)

- Self-expression - using the prosthetic as a platform for the child to take ownership either through choosing the appearance at the point of fitting (Projects 009, 014, 020), or by continually engaging with the limb through Lego (Project 002).

- Accommodating real-world activities - for example tying laces, sitting on the floor, getting wet/muddy, etc. (Project 010)

\section{Potential transferrable benefits to adult services}

As part of their final report, PoC projects were asked if any of the insights or innovation from their exploratory work could be transferred to adult populations also. Suggested transferrable benefits included:

- Enhanced socket fit (001) (014). According to project 001, a recent study described how, 'Up to $90 \%$ of adult amputees reported socket discomfort due to poor socket fit.' As such, the potential benefit of this work to the wider population of prosthetic limb users is large.

- Enhanced understanding of stump volume change throughout the day could lead to the development of smart devices that adapt to these changes (016)

- Enhanced training, uptake and functionality of electronic upper limb prosthetics (006) (018).

\section{New unmet needs identified by the PoC projects}

The PoC projects' final report also prompted the teams to suggest any further unmet needs that have arisen during the course of their work, described below:

- The commercial market currently lacks a body-powered (mechanical) children's hand that operates with a low enough pull force, is lightweight, and looks good (Project 002).

- There is a 'critical need' for a low-cost active upper-limb prosthetics (i.e. electronic devices) for younger children. Some of the more popular models are intended for children above the age of 9 , however this may be too late too late to provide the unctional gains necessary to avoid musculoskeletal problems associaled with overuse of the intact limb: Project 006, who identified this need, intend to explore this

- Key factors in the personalisation of a prosthetic socket, including fitting and comfort, are "currently unquantifiable or difficult to describe/interpret as engineering parameters.' Project 014, who identified this need, intend to explore this further.

\section{Challenges experiences by the Starworks PoC projects}

Regarding the involvement of children and families

The Starworks Team encouraged the PoC projects to involve children and families as much as possible in their projects, and provided support where needed. Nevertheless, PPI can stil be a demanding process - some of the key challenges encountered by the projects include:

- Making initial contact with families, i.e. through charitable bodies (006)

- The practicalities of arranging their involvement $-i$.e. finding home visiting times that avoid any disruption to school education and family commitments. (001)

- One project identified that younger children are less forgiving of a 'minimum viable product' when testing prototypes, and that 'certain levels of engagement are necessary before actively working with younger age groups,' (006). 
- Long lead time can prevent useful validation studies being conducted. For example 001 stated, 'We would like to conduct clinical studies involving children amputees so that efficacy of SIMS could be evaluated. However, this was not practically possible in this project due to the need of NHS ethics approval.' (001) (014) (020)

- Unfamiliarity with NHS ethics approval process were also raised as a concern in the Industry Forum meetings, described in more detail in Appendix 2.

\section{Project duration}

encountered challenges due to the relatively short duration of the PoC

unding duration. For example:

- Several studies stated that the relatively short duration of the project caused issues for involving children and families, and the necessary ethics application processes. (001) (018). In light of this, Project 001 requested and was granted a 3-month unfunded extension to accommodate some delays in children volunteer recruitment, as well as disseminate their work more widely. (001)

The ordering of specialist equipment to support the research can also cause unexpected delays to projects (006)

- The recruitment of Research Assistants in short-term projects such as this can be challenging (018).

\section{Recommendations from the Starworks PoC projects}

- Allow longer project run times when commissioning research in this area (001). This may also better support the involvement of clinicians in research, who generally cannot take out much time out of their workload each week for this activity (002).

- Provide support and guidance/signposting on when ethical approvals are needed, for what activities, and when to initiate these applications (with project-based, practical support when needed). (001)

- Guidance and training in research ethical approval processes may be particularly important if clinicians (with less research experience) are leading research projects, as highlighted in the following quote from $\mathrm{PoC} 002$ ' 'They are simply not equipped with either the time or experience to manac the , 'They are simply not equipped with either the the oxp and processes without significant lovels of training and support from their employers - and since such support would mean taking clinicians away from their regular duties of direct patient care it is hard to see such support being forthcoming... It may prove more practical and effective if researchers with the skills and support to drive such projects engage more with frontline clinicians, using their clinical skills and experience to find innovations that they are then able to take further." 
Appendix 2:

Outcomes and Added Value from the Industry Forums

As outlined in the main text of this report, a successful application to The University of Sheffield's MRC Proximity to Discovery (P2D) funding led to The Starworks Team hosting two 'Industry Forum' meetings for the Stanworks Proof of Concept (PoC) projects. The meetings took place on $9^{\text {th }}$ July 2018 and $20^{\text {th }}$ October 2018 in Sheffield, and were a chance for the PoC project teams to meet each other as well as academics working in related fields, discuss their experiences so far, problem-solve the challenges they have faced and offer opportunities for collaboration.

The following summary outlines the main outcomes and added value of these meetings.

\section{Outcomes}

Multiple knowledge exchange activities have been undertaken, these include two 4 hour workshops and an active online facilitation approach.

The meetings included presentations from all the proof of concept projects on their objectives and technical approaches and challenges faced (challenges utilise the expertise available through the P2D initiative.

- $\quad$ Academics from the University of Sheffield and Sheffield Hallam University presented on their areas of expertise. Attendees then had round table discussions for collaboration, whilst considering the challenges outlined.

Colleagues with necessary expertise (i.e. regulatory guidance) attended the meetings to offer targeted advice as needed.

- $\quad$ Outputs from each group were reported after each meeting, and offered a focus on defining specific opportunities/areas for collaboration and unexpected benefits of these meetings.

- As anticipated, by bringing various experts together to share and collaborate, issues identified by the proof of concept projects at this stage in development were supported and advice given. This included areas around regulatory issues, families.

Reports from each meeting are available on request.

Added value - Regulatory and ethical issues

It was clear not only from our work engaging all the stakeholders but also from applications to the PoC funding call that there is uncertainty regarding the regulatory requirements relating to limb prostheses (within and outside of EU) and of the impending impact of the Medical Device Regulation (EU 2017/745; MDR). This was Universities).

- In addition, it became apparent that some providers of limb prostheses for children, and those delivering clinical care for young prosthesis users, may not be fully aware of ethical requirements processes for research. In particular, distinctions between NHS and academic ethics and understanding the boundaries and differences between standard clinical practice, service evaluation and research.

- The time needed for NHS ethics application processes were a key challenge for several projects (as discussed in Appendix 1)

- Some of the regulatory uncertainty arises from Not appreciating the need for a stated 'intended purpose' for a prosthetic device classification. The Starworks projects provided real examples emonstrating the impact on classification, particularly in the area of innovations with potential to qualify as medical device accessories Innovators not having a background in medical devices

Innovators pushing the boundaries and challenging current regulatory frameworks

- Use of novel manufacturing techniques and materials, such as additive manufacture (3D printing, etc.) and implication for quality and process Ussurance (e.g. load-testing, biocompatibility for new sockets) and understanding how to meet current Essential Requirements and upcoming Safety \& Performance Requirements, including for non-CE marked devices (custom-made or investigational)

marketed consumer tracking products for .

Ongoing consultations relating to future healthcare institution requirements (e.g. mandatory quality management systems such as ISO 13485:2016) fo in-house manufactured custom-made medical devices

Needing to understand impact of device integration e.g. compatibility of systems which might interact with components from different manufacturers

Understanding the impact and risk-benefits of designing to permit non-

professional adaptations (e.g. for growth, oedema)

Different uses of embedded software and sensors within prostheses for unction and versus evidence generation (usage, value, post market surveillance, etc.)

Evolutions in custom-made implants (e.g. extended application of percutaneous osseo-integrated limb prosthetics - currently for adults and

In conjunction with the Medicines and Healthcare products Regulatory Agency produce a number of recommendations and support documents to disseminate the knowledge gained more widely.

Some of the ethical uncertainty arises from:

The funding call provided a rare opportunity for frontline clinicians such as prosthetists and enthusiastic 'lay' innovators to get involved in research for the first time. Due to the contractual arrangements for NHS prosthesis provision, many prosthetists are employed by prosthetics manufacturers and do not necessarily understand NHS research processes as this would not be part of their typical provision.

Other Challenges

poject-specific challenges that emerged during the Industry Forums included:

How to design child-friendly, engaging software interfaces? (Project 001, Project 006 and Project 020)

How complex should they be?

input early enough in the design of these Licensing may

be difficult process further down the line

How to find a balance between children's engagement and parents' preferences? 
With regards to fit and comfort of sockets, there is somewhat of a methodological tension between traditional casting techniques and 3D scanning-based

development of sockets [010] [016] [020]. Whilst the former often delivers better results, it requires prosthetists with appropriate training and experience. $3 \mathrm{D}$

scanning techniques open up possibilities for children and families to take more ownership of the fitting process, as well as new avenues of personalisation, but as yet the technology does not deliver the same levels of consistency, comfort and fit as casting.

- In projects involving cosmetic customisation, copyright may become an issue -

how to find a balance between offering children designs featuring characters they love without breaching copyright?

- $\quad$ Considering the needs of parents was also raised as a potential challenge - in some instances, it has been found that children and their parents may have differing wants or needs.

Unsurprisingly some of the challenges outlined by projects in their final reports (detailed in

Appendix 1) were also part of the discussion at the Industry Forum meetings, in particular

how to best engage children and families in the research process in an ethical, effective and fun way. 


\section{Appendix 3: Images for the Starworks Celebration Event}

Images from the Starworks Celebration Event, 25th March 2019

Drawings by Sarah 'Smizz' Smith, www sarahsmizz com

Photographs by Devices for Dignity, devicesfordignity.org.uk
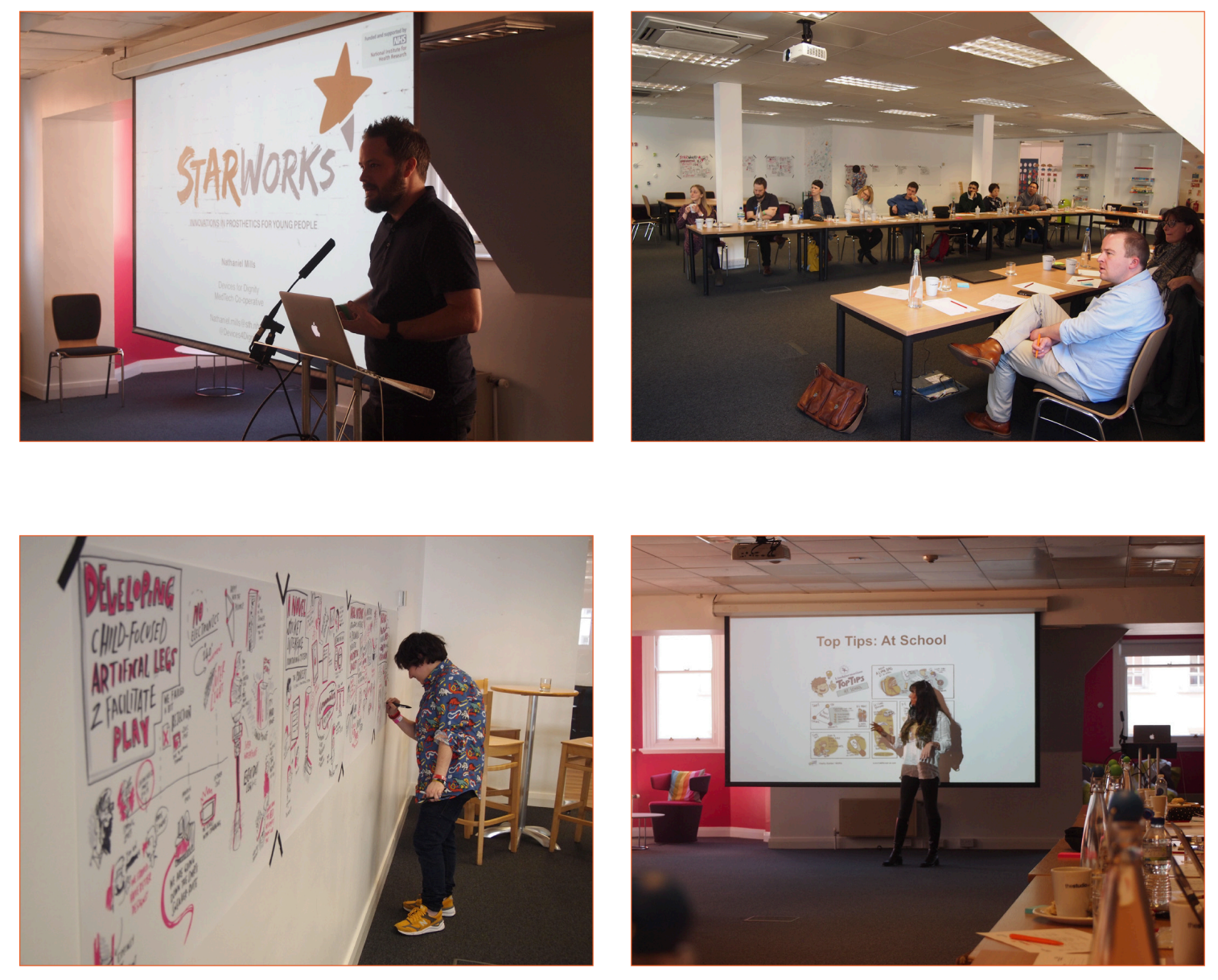

Project 001

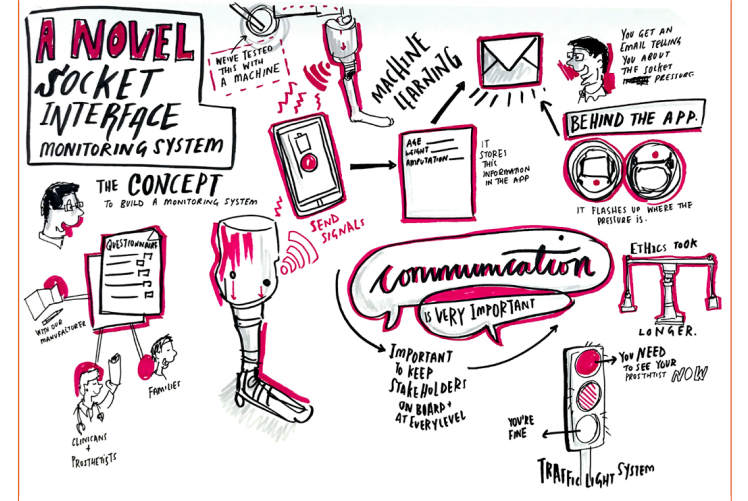

Project 004

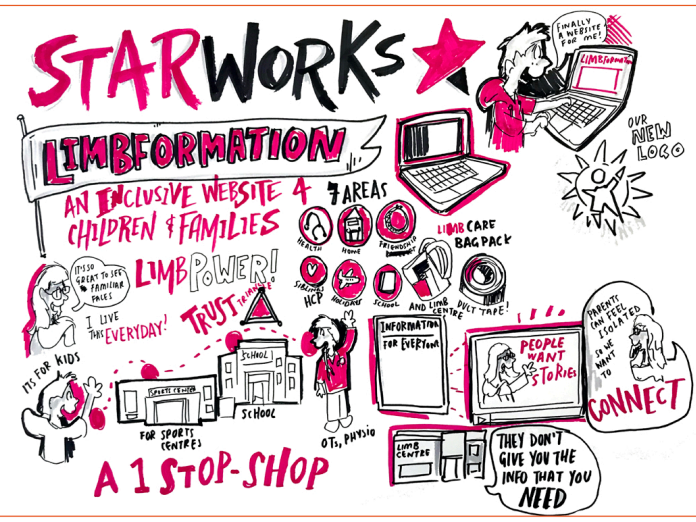

Drawings by Sarah 'Smizz' Smith, www sarahsmizz com Photographs by Devices for Dignity, devicesfordignity.org.uk
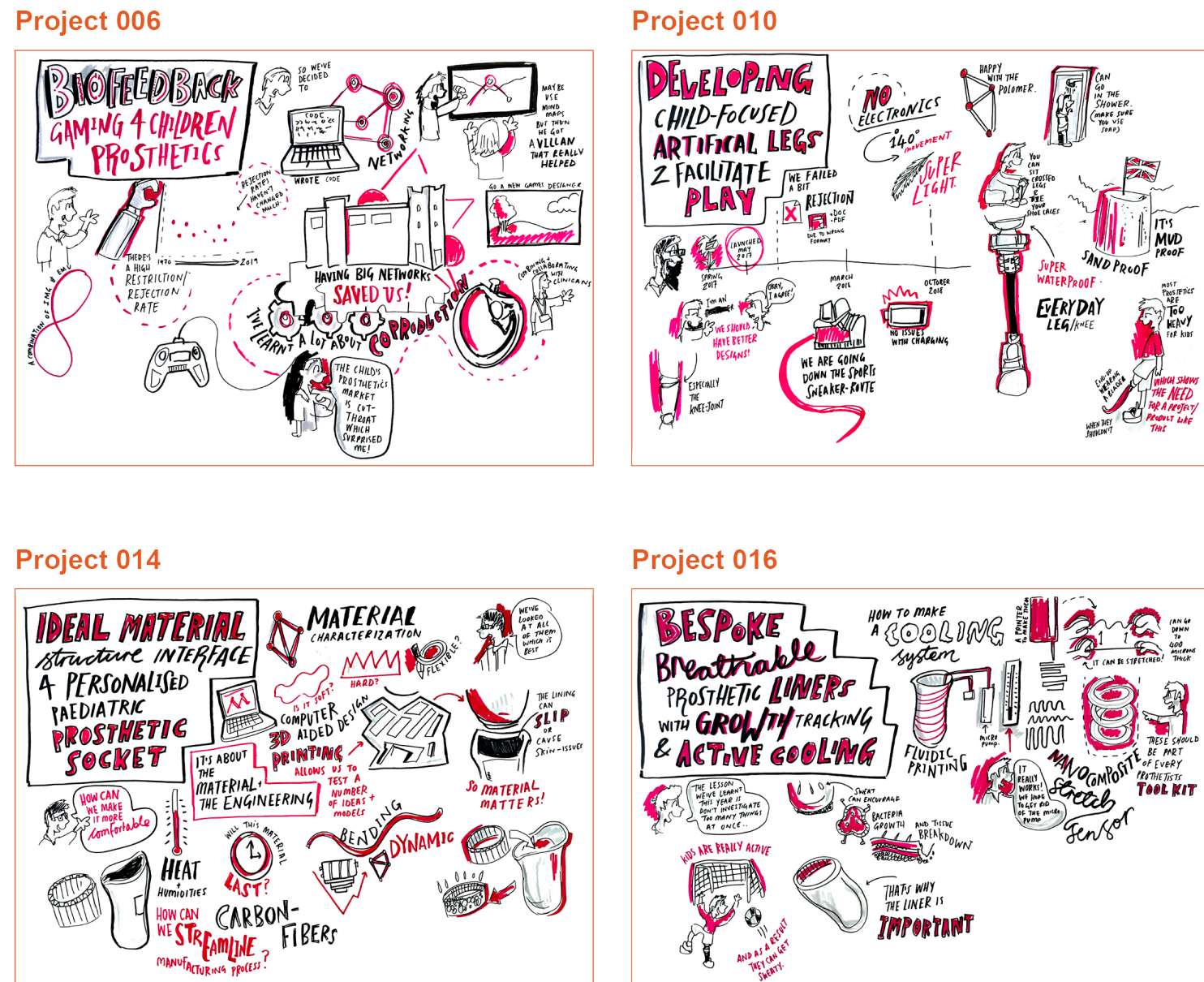

Project 016

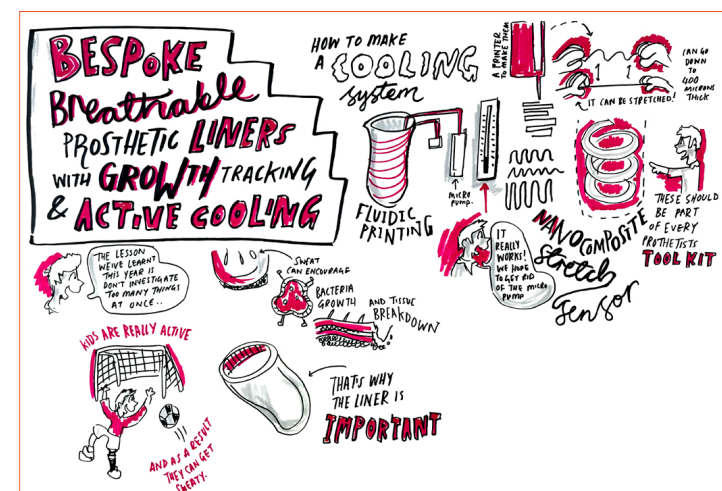

Project 018

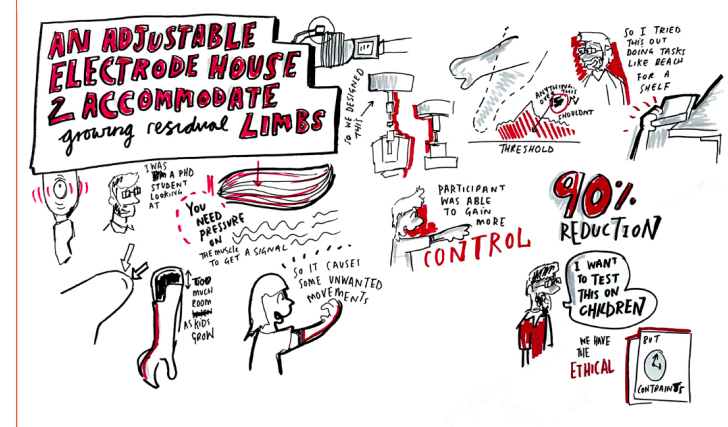

Project 020

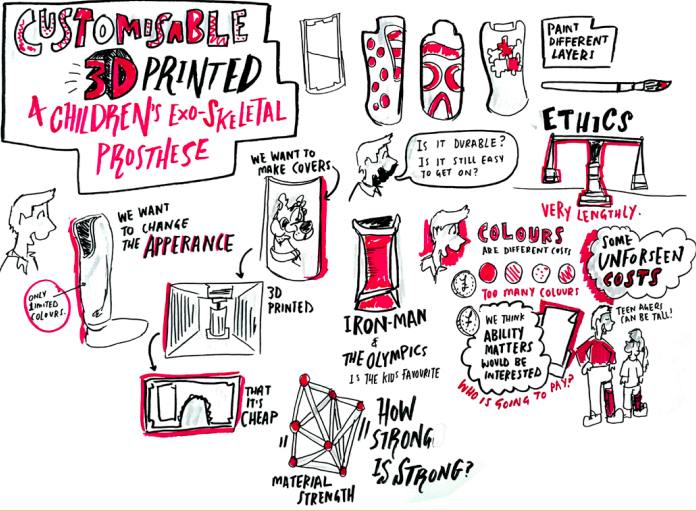




\section{Appendix 4: Tools created to collect feedback or ideas from children and}

families

Project 006 - Poster display

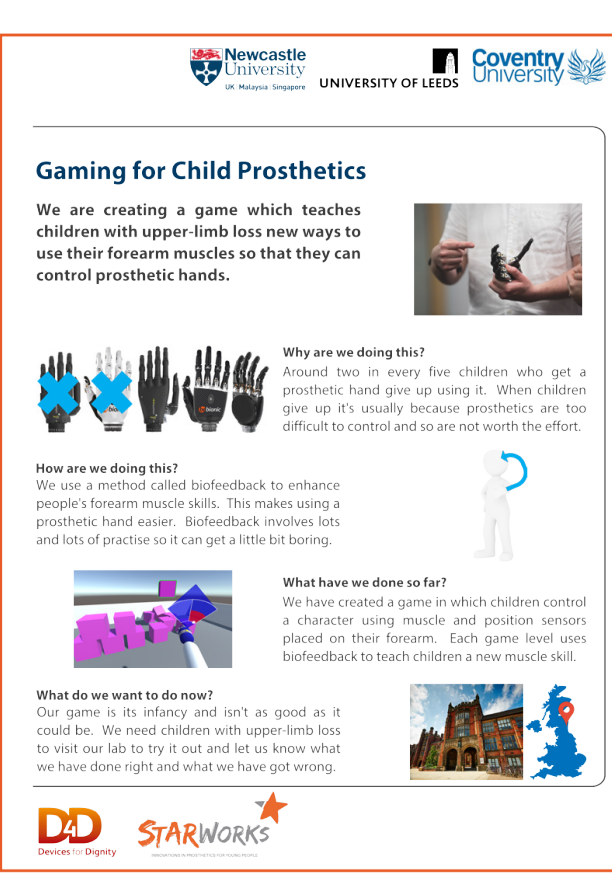

Front cover of the 'Activity Pack' distributed online during the Christmas school holidays via D4D networks

Wishing you a
Merry Christmas
from

Project 009 - Feedback forms and activity sheets
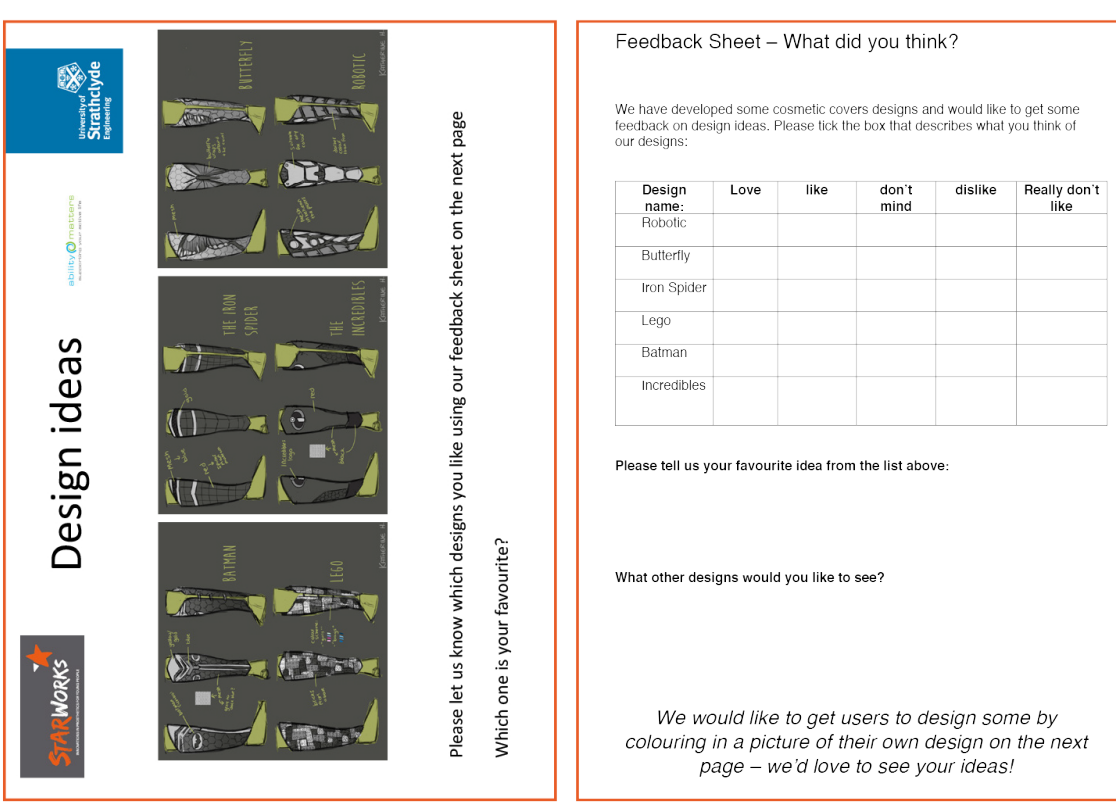

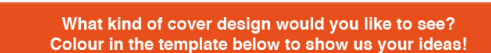
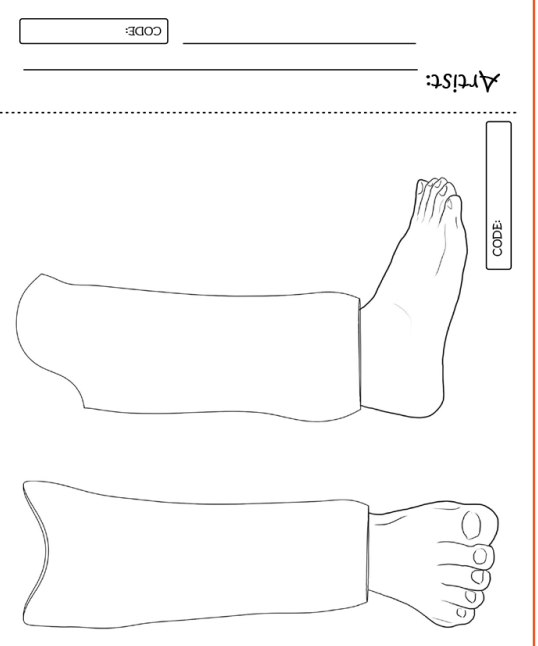

Project 009 - Feedback forms and activity sheets
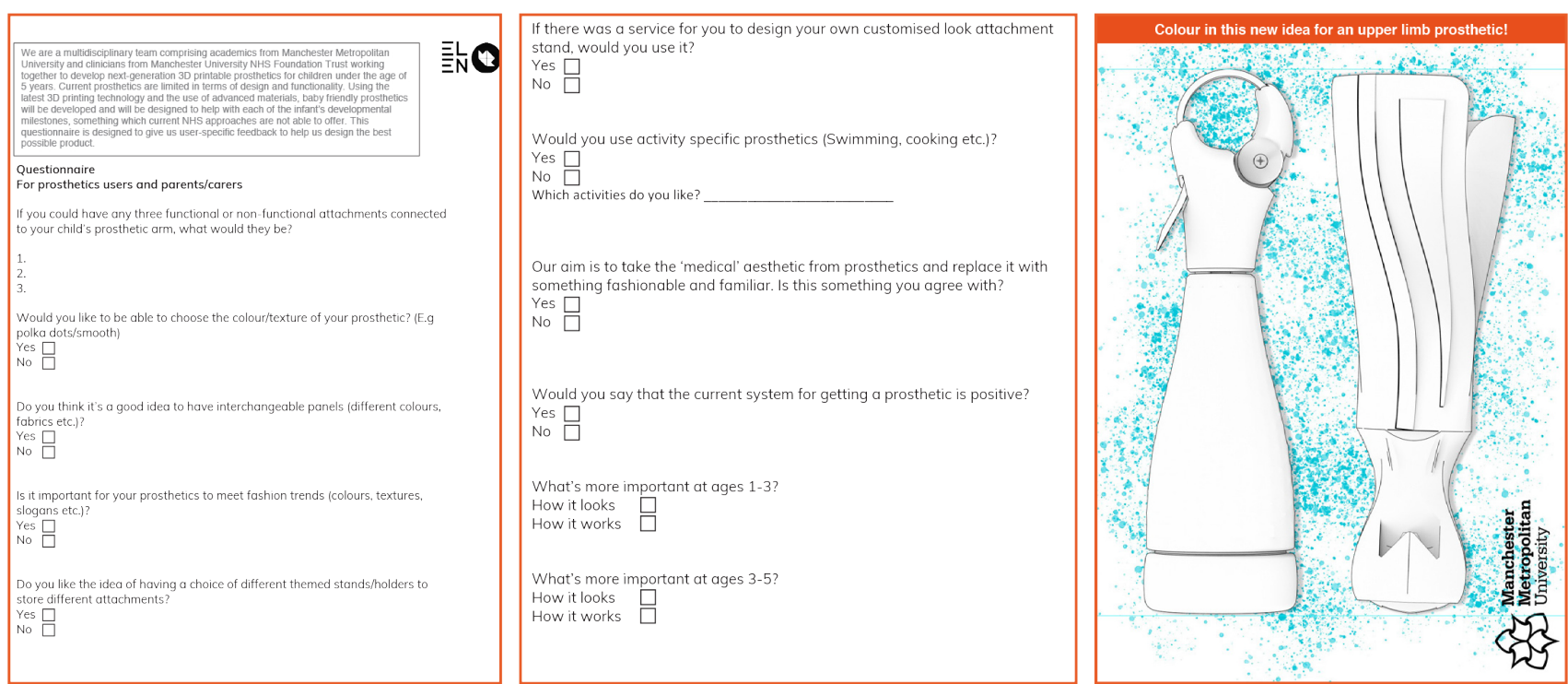

Project 014 - Feedback forms and activity sheets

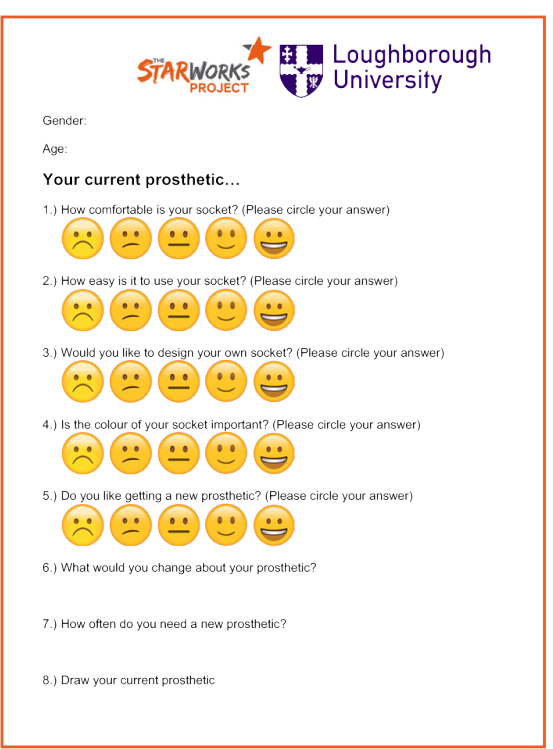




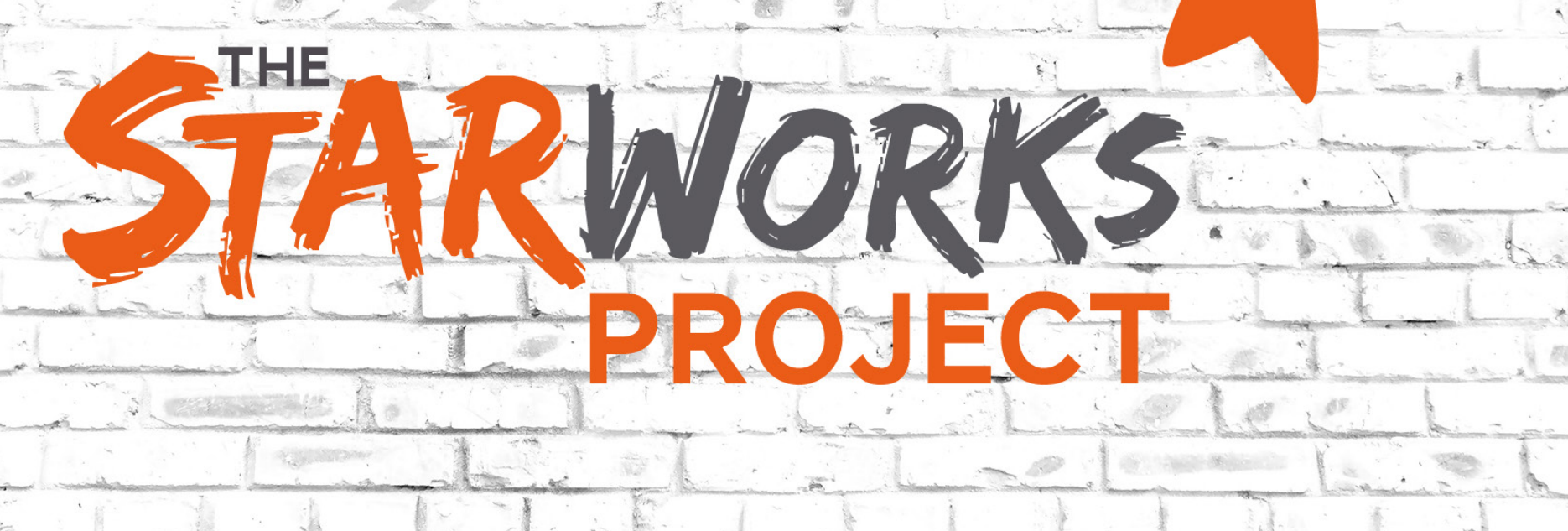

INNOVATIONS INPROSTHETICS FOR YOUNG PEOPLE 


\section{Sheffield Hallam University}

The Starworks Project: Annual Report to National Institute for Health Research 2018-2019 WHEELER, Gemma, MILLS, Nathaniel and LANGLEY, Joseph

Available from the Sheffield Hallam University Research Archive (SHURA) at: http://shura.shu.ac.uk/27852/

\section{Copyright and re-use policy}

Please visit http://shura.shu.ac.uk/27852/ and http://shura.shu.ac.uk/information.html for further details about copyright and re-use permissions. 